\title{
A Review on Montmorillonite-Supported Nanoscale Zerovalent Iron for Contaminant Removal from Water and Soil
}

\author{
Yaru Yin $\mathbb{D}^{1},{ }^{1}$ Wenjuan Zheng, ${ }^{2}$ An Yan $\mathbb{D}^{3}{ }^{3}$ Chenxi Zhang, ${ }^{1}$ Yuxuan Gou, ${ }^{1}$ \\ and Chongyang Shen $\mathbb{i}^{1}$ \\ ${ }^{1}$ Department of Soil and Water Sciences, China Agricultural University, Beijing 100193, China \\ ${ }^{2}$ Department of Mechanics and Aerospace Engineering, Southern University of Science and Technology, Shenzhen, \\ Guangdong 518055, China \\ ${ }^{3}$ College of Grassland and Environmental Science, Xinjiang Agricultural University, Urumqi, Xinjiang 830052, China
}

Correspondence should be addressed to An Yan; zryanan@163.com and Chongyang Shen; chongyang.shen@cau.edu.cn

Received 1 June 2021; Accepted 4 August 2021; Published 27 August 2021

Academic Editor: Xue Tao Guo

Copyright ( 2021 Yaru Yin et al. This is an open access article distributed under the Creative Commons Attribution License, which permits unrestricted use, distribution, and reproduction in any medium, provided the original work is properly cited.

\begin{abstract}
Nanoscale zerovalent iron (nZVI) has shown great promise for water treatment and soil remediation. However, the rapid aggregation of nZVIs significantly affects their mobility and reactivity, which considerably limits the practical applications. Montmorillonite- (Mt-) supported nZVI (Mt-nZVI) has received increasing attention for the past decade because it can prevent the aggregation of nZVI and incorporate the advantages of both nZVI and Mt in soil and water treatment. This work thus had a comprehensive review on the use of Mt-nZVI for soil and water treatment. We first summarized existing methods used to prepare Mt-nZVI, indicating the advantages of using Mt to support nZVI (e.g., increase of the dispersion and mobility of nZVI, reduction of the size and oxidation tendency of $\mathrm{nZVI}$ ). We then presented the reaction mechanisms of Mt-nZVI for contaminant removal and evaluated the critical factors that influence the removal (e.g., $\mathrm{pH}$, temperature, and dosage of the adsorbent). We further presented examples of applications of Mt-nZVI for the removal of typical contaminants such as heavy metals and organic compounds in soil and water. We finally discussed the limitations of the use of Mt-nZVI for water treatment and soil remediation and presented future directions for the application of nZVI technology for soil and water treatment.
\end{abstract}

\section{Introduction}

Water and soil contaminations are becoming more and more severe during the past few decades, which seriously damage the natural ecological balance and threaten human health [1]. Various techniques such as ion exchange, filtration, chemical precipitation, and electrochemical treatment have been employed to address the water and soil contaminations [2-4]. However, these techniques have a series of limitations including high cost, secondary pollution, and complicated operations [5]. Recently, the fabrication of adsorption materials with low cost and high performance for the treatment of soil and water has become a promising way [6]. Particularly, the use of nanoscale zerovalent iron (nZVI) has received focused attention [7].

The nZVIs refer to nanoscale iron particles with amorphous structures, which have been widely applied to remove various contaminants because of their large specific surface area (SSA), strong adsorption activity, and reduction ability $[8,9]$. However, nZVI tends to agglomerate into larger particles due to van der Waals and magnetic forces, which decreases the SSA and limits its adsorption capacity and mobility [10]. Moreover, nZVI is readily oxidized before reaching the target contaminants during in situ soil remediation, resulting in low longevity [11]. An effective approach to overcome the aforementioned problems is to load nZVI particles onto templates such as biochar [12], zeolite [13], and polymers [14]. Nevertheless, these templates need to be manufactured and/or are relatively expensive, and the fabrications are often complex [15]. Therefore, it is desirable to find low-cost load materials and develop more efficient methods of immobilization of nZVI on templates to take advantage of the real potential of nZVI [16]. 
Montmorillonite (Mt) is a typical 2:1 layered silicate clay mineral with low cost, high cation exchange, and adsorption capacity (Figure 1) [17]. It is usually composed of an interlayer with a thickness of $0.1-0.8 \mathrm{~nm}$ due to the isomorphous substitution within the layers (e.g., $\mathrm{Si}^{4+}$ replaced by $\mathrm{Al}^{3+}$ in the tetrahedral sheet and $\mathrm{Al}^{3+}$ replaced by $\mathrm{Mg}^{2+}$ in the octahedral sheet) (Figure 1). Hence, the Mt layers have permanent negative charges, which can be exchanged by other cations residing at and/or near the Mt surfaces [18]. This structure creates an ideal template to support nZVI particles (Figure 2) [19]. For example, bentonite (Bt) is a kind of natural clay mainly composed of $\mathrm{Mt}$, which has been extensively used as a supporting material for nZVI [20]. Compared to nZVI or Mt, Mt-supported nZVI (Mt-nZVI) had higher removal efficiency for inorganic and organic contaminants [21-23]. This is because Mt can improve the dispersion and mobility of nZVI and reduce the particle size and oxidation tendency of nZVI [24-26]. Therefore, the Mt-nZVI composites have shown great potential for application in water and soil treatment.

To date, various papers have made reviews on the synthesis, characteristic, application, or modification of nZVI (Table 1) $[1,27,28]$. For instance, Li et al. [8] presented the synthesis, characterization, and applications of nZVI for the treatment of organic and inorganic contaminants. O'Carroll et al. [29] reviewed the application of nZVI and bimetallic particles. Lefevre et al. [30] summarized the impacts of nZVI applications on microbial communities. Ezzatahmadi et al. [31] reported an overview of different types of claysupported nZVIs (e.g., Mt, kaolinite, zeolite, sepiolite, and palygorskite) for the remediation of contaminated aqueous solutions. However, no review has exclusively addressed the use of Mt-nZVI for soil and water remediation to date.

This paper provides an overview of the current knowledge of Mt-nZVI composites in water and soil applications. We firstly present the preparation methods of Mt-nZVI and discuss the advantages and disadvantages of the different methods. We highlight the benefits of using Mt as supporting material for nZVI. We then show in detail the reaction mechanisms of Mt-nZVI for contaminant removal and the main influencing factors on the removal using the Mt-nZVI. We further give examples of the applications of Mt-nZVI in soil and water remediation. We finally demonstrate the limitations of Mt-nZVI composites and show future research directions. Our work has important implications to improve the Mt-nZVI composites for application in water treatment and soil remediation.

\section{Fabrication Methods of Mt-nZVI}

2.1. Methods of Synthesizing Modified Mt. The properties of Mt have a great influence on the application of Mt-nZVI. The pristine $\mathrm{Mt}$ is commonly Ca-Mt, which has a permanent negative charge. Positively charged hydrated cations (e.g., $\mathrm{K}^{+}$, $\mathrm{Na}^{+}$, and $\mathrm{Ca}^{2+}$ ) can be adsorbed in the layers to maintain charge balance [32]. These cations can be exchanged by other organic/inorganic cations, making Mt an efficient adsorbent for cationic contaminants [33].

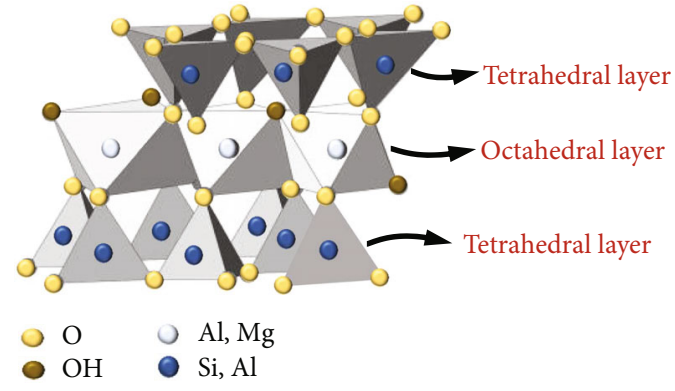

Figure 1: Structure of Mt. Modified from Reinholdt et al. [110].

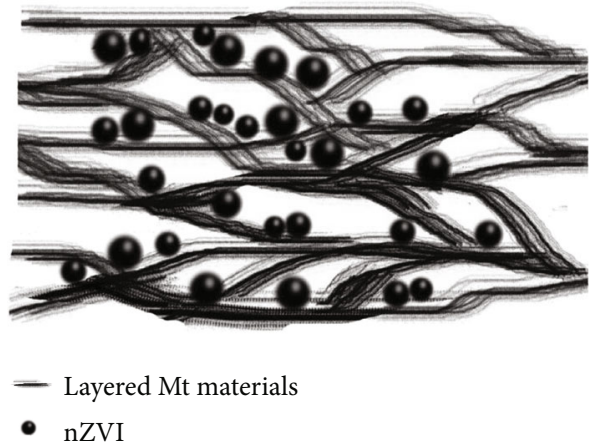

FIGURE 2: Schematic representation of the sectional structure of Mt-nZVI. Modified from Wu et al. [43].

2.1.1. Inorganic Modified Mt. Na-Mt has better physicochemical properties compared to $\mathrm{Ca}-\mathrm{Mt}$, such as strong cation exchangeability, high dispersion in the water medium, large expansion capacity, and great thermal stability [34]. Therefore, Na-Mt is frequently used as the raw material to prepare Mt-nZVI. Alternatively, K-Mt [21] and Al-Mt [33] have also been used to synthesize Mt-nZVI.

Due to electrostatic interaction, the negatively charged Na-Mt-supported nZVI normally favors the adsorption of cationic contaminants $[33,35]$, while the positively charged K-Mt- and Al-Mt-supported nZVIs favor the adsorption of anionic contaminants [21, 33, 36]. For example, Sheng et al. [25] revealed that the removal efficiency of $\mathrm{U}(\mathrm{VI})$ $\left(100 \mathrm{mg} \mathrm{L}^{-1}\right)$ by Na-Bt-supported nZVI $\left(0.2 \mathrm{gL}^{-1}\right)$ reached 99.2\% after $90 \mathrm{~min}$, which was higher than that by Al-Btsupported nZVI (65.6\%) (Table 2). Li et al. [35] found that $\mathrm{Na}$-Bt-supported nZVI had higher removal efficiency for $\mathrm{Ni}$ (II) (98.5\%) compared to Al-Bt-supported nZVI (45.4\%) under the same condition (Table 2). However, the removal efficiency of K-Mt-supported nZVI and Al-Mt-supported nZVI for $\mathrm{Cr}(\mathrm{VI})$ was higher than that of Na-Mt-supported nZVI [21]. The method of inorganic modification of Mt is relatively simple, which can improve the adsorption of MtnZVI to target inorganic contaminants.

2.1.2. Organic Modified Mt. While Mt is hydrophilic and negatively charged, organic contaminants are usually hydrophobic [37]. Consequently, some nonionic or anionic organic compounds have poor adsorption affinity with Mt-nZVI [38]. To overcome the limitations, cationic surfactants have 
TABLE 1: Summary of some key review papers on nZVI for water and soil treatments.

\begin{tabular}{|c|c|c|c|}
\hline $\begin{array}{l}\text { Publication } \\
\text { date }\end{array}$ & Material & Focus area & Reference \\
\hline 2006 & nZVI & $\begin{array}{l}\text { Synthesis, characterization, and applications of nZVI for the treatment of organic and } \\
\text { inorganic contaminants }\end{array}$ & {$[8]$} \\
\hline 2012 & $\mathrm{nZVI}$ & Synthesis and applications of nZVI for water treatment & [27] \\
\hline 2013 & $\begin{array}{l}\text { nZVI/bimetallic } \\
\text { nanometals }\end{array}$ & $\begin{array}{l}\text { Application of nZVI/bimetallic nanometals for the in situ remediation of chlorinated } \\
\text { solvents and heavy metals }\end{array}$ & [29] \\
\hline 2013 & nZVI & $\begin{array}{c}\text { Reactivity, stability, and effects of nZVI amendment on the } \\
\text { biogeochemical environment }\end{array}$ & {$[52]$} \\
\hline 2016 & $\mathrm{nZVI}$ & Impacts of nZVI applications on microbial communities & {$[30]$} \\
\hline 2016 & nZVI & $\begin{array}{l}\text { The toxicity of nZVIs prior to the process of remediation and their effect on living } \\
\text { organisms after application }\end{array}$ & {$[28]$} \\
\hline 2016 & nZVI & Synthesis, applications, and properties of stabilized nZVI & [47] \\
\hline 2017 & Clay-supported nZVI & $\begin{array}{l}\text { Reaction mechanisms and removal efficiencies of clay-supported nZVI for the } \\
\text { remediation of contaminated aqueous solutions }\end{array}$ & {$[31]$} \\
\hline 2019 & Biochar-supported nZVI & $\begin{array}{l}\text { Synthesis, properties, and applications of biochar-supported nZVI for water and } \\
\text { soil treatment }\end{array}$ & {$[12]$} \\
\hline 2019 & nZVI & $\begin{array}{c}\text { Synthesis of nZVI-based materials and reaction mechanisms and influential factors } \\
\text { between nZVIs and antibiotics }\end{array}$ & {$[46]$} \\
\hline
\end{tabular}

been used as modifiers of Mt [39]. Quaternary ammonium salt cations are common cationic surfactants such as cetyltrimethylammonium (CTMA) [40,41], cetyltrimethylammonium bromide (CTMAB) [26, 42], and hexadecyltrimethylammonium bromide (HDTMA) [43].

The advantages of using organic modified Mt-supported nZVI to remove organic compounds have been reported. Substituting the inorganic cations (e.g., $\mathrm{Na}^{+}$) with organic ammonium cations (e.g., $\mathrm{DTA}^{+}$) in the Mt interlayer can further increase the layer spacing and enhance the adsorption capacity of organic contaminants on Mt by changing the surface of Mt from hydrophilic to hydrophobic [19, 42, 44]. For example, Li et al. [40] reported that the efficiency of pentachlorophenol $\left(53 \mathrm{mg} \mathrm{L}^{-1}\right)$ removed by CTMAmodified Bt-supported $\mathrm{nZVI}\left(0.6 \mathrm{~g} \mathrm{~L}^{-1}\right)$ reached $96.2 \%$ within $120 \mathrm{~min}$ at $\mathrm{pH} 6$, which was higher than that by Bt-nZVI (49.6\%). Moreover, the degradation efficiency of decabromodiphenyl ether (DBDE) by tetramethylammonium- (TMA-) modified smectite-supported nZVI was 10 times greater than that by nZVI. Note that the organic modified Mt can also inhibit the rapid consumption of nZVI by forming a hydrophobic environment in the clay interlayer. For example, Jia and Wang [19] used N,N,N-trimethyl-1-dodecanaminium salt- $\left(\mathrm{DTA}^{+}-\right.$) modified smectite-supported nZVI to remove 2,4-dichlorophenol (2,4-DCP) and found that almost $100 \%$ of 2,4-DCP could be dechlorinated even after five cycles on organo-smectite-supported nZVI, but smectite-supported nZVI only dechlorinated twice.

\subsection{Methods of Synthesizing Mt-nZVI}

2.2.1. Liquid-Phase Reduction. Wang and Zhang [45] were the first to develop a liquid-phase reduction method to prepare nZVI. This technique has then become the most widely used method to prepare nZVI in laboratories [46]. In this approach, nZVI is synthesized by reduction of $\mathrm{Fe}^{3+}$ or $\mathrm{Fe}^{2+}$ in aqueous solutions using $\mathrm{NaBH}_{4}$ under $\mathrm{N}_{2}$ atmosphere (Equations (1) and (2)) [31, 47]:

$$
\begin{aligned}
& 4 \mathrm{Fe}^{3+}+3 \mathrm{BH}_{4}{ }^{-}+9 \mathrm{H}_{2} \mathrm{O} \longrightarrow 4 \mathrm{Fe}^{0}+3 \mathrm{BO}_{3}{ }^{-}+12 \mathrm{H}^{+}+6 \mathrm{H}_{2} \\
& 2 \mathrm{Fe}^{2+}+\mathrm{BH}_{4}{ }^{-}+3 \mathrm{H}_{2} \mathrm{O} \longrightarrow 2 \mathrm{Fe}^{0}+\mathrm{BO}_{3}{ }^{-}+4 \mathrm{H}^{+}+3 \mathrm{H}_{2}
\end{aligned}
$$

The Mt-nZVI is synthesized by a slightly modified liquidphase reduction method with $\mathrm{Mt}$ as support [21]. Briefly, MtnZVI is typically prepared under $\mathrm{N}_{2}$ atmosphere by using $\mathrm{NaBH}_{4}$ to reduce $\mathrm{Fe}^{3+}$ or $\mathrm{Fe}^{2+}$ to $\mathrm{Fe}^{0}$ in the presence of $\mathrm{Mt}$ as the supporting material (Figure $3(\mathrm{a})$ ). The $\mathrm{Mt}$ is used as a layered template to limit the size of the nZVI formed at the nanoscale $(60-80 \mathrm{~nm})$ and direct the distribution of nZVI clusters [19, 48-50]. The scanning electron microscope (SEM) images of Bt-supported nZVI (Bt-nZVI) (Figure 4(a)) synthesized by the aforementioned method showed that the aggregation of nZVI particles was decreased due to Bt [51]. Various organic or inorganic modifiers can be used to modify Mt before the preparation of Mt-nZVI to improve its adsorption performance and dispersibility in organic media [33], which are detailed later in the paper.

There exist several drawbacks to the liquid-phase reduction method. First, it is relatively expensive due to the high cost of $\mathrm{NaBH}_{4}$ [52]. Second, $\mathrm{NaBH}_{4}$ may destroy some chemical bonds in $\mathrm{Mt}$ or $\mathrm{Bt}$, resulting in a change of the proportion of Mt or Bt [50]. Third, the nZVI is hard to be evenly distributed on the template surfaces. For example, Wang et al. [53] prepared Mt-nZVI and observed that more nZVI particles were dispersed at the edge of the $\mathrm{Mt}$, and few particles were distributed in the middle part of Mt. This ununiform distribution of nZVI on template surfaces could affect the mobility of the composite in the environment because the distribution 


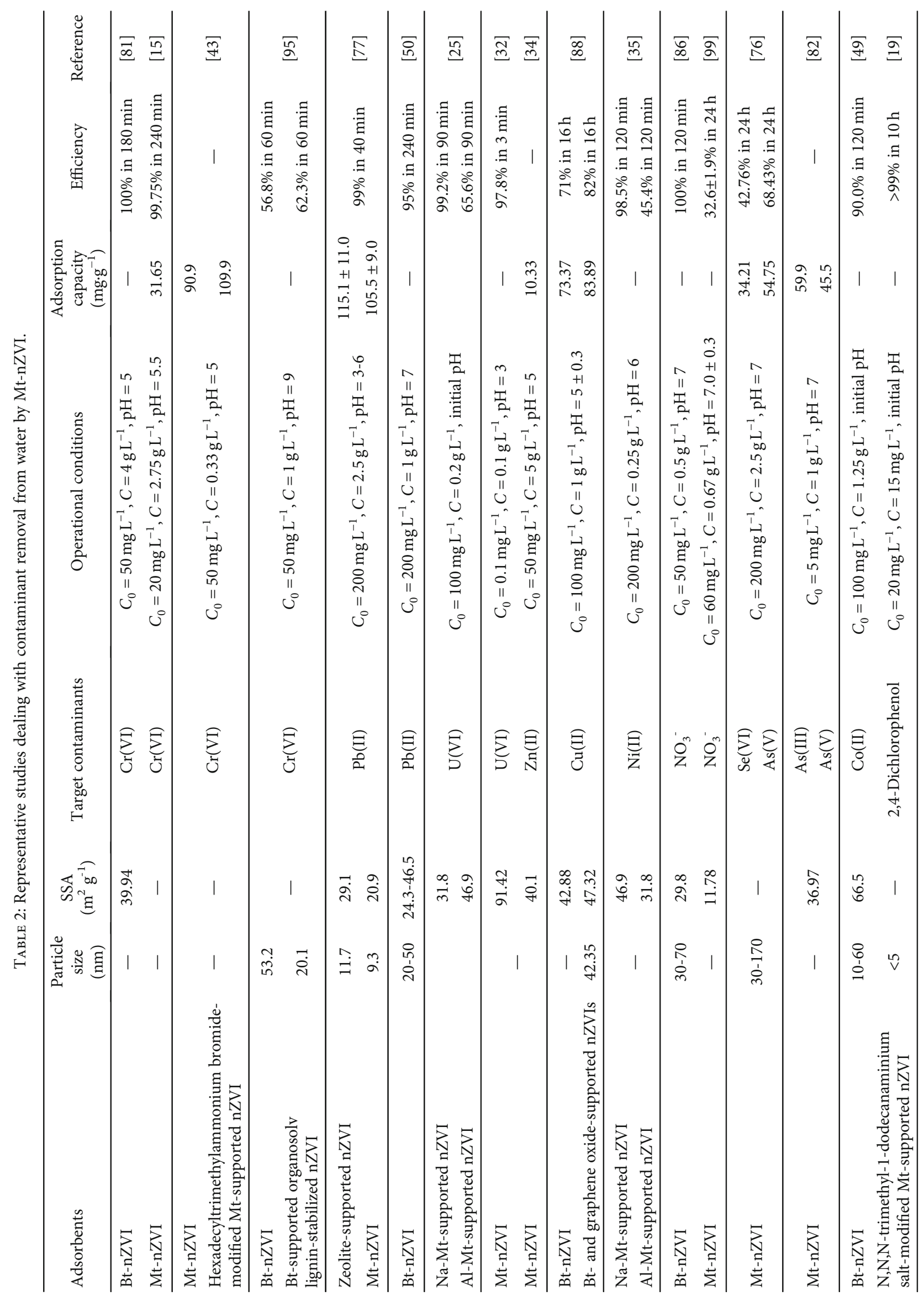




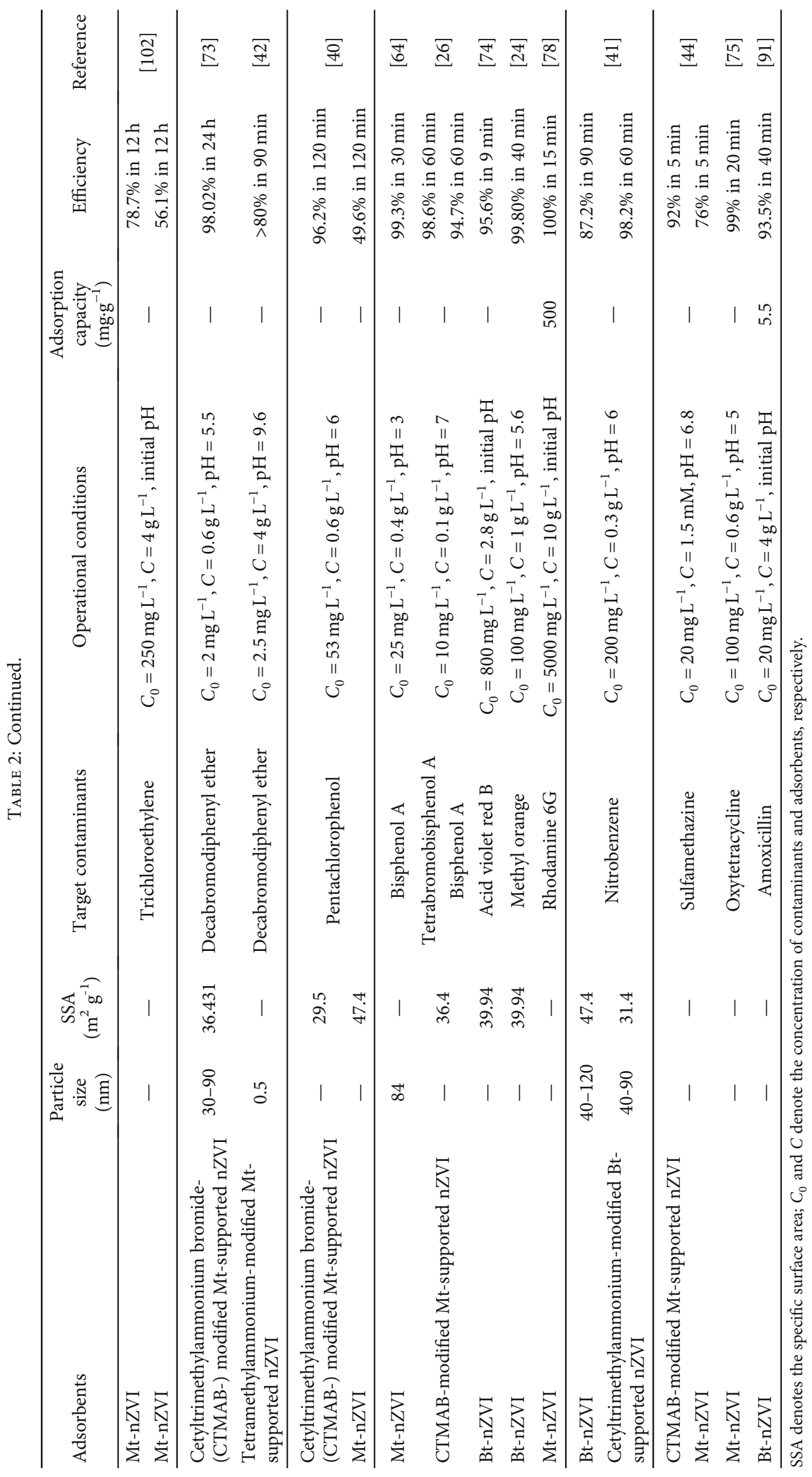




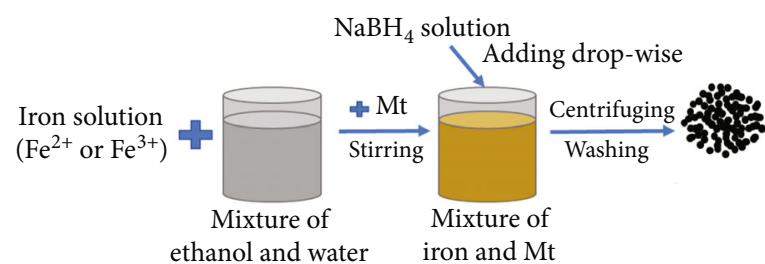

(a)

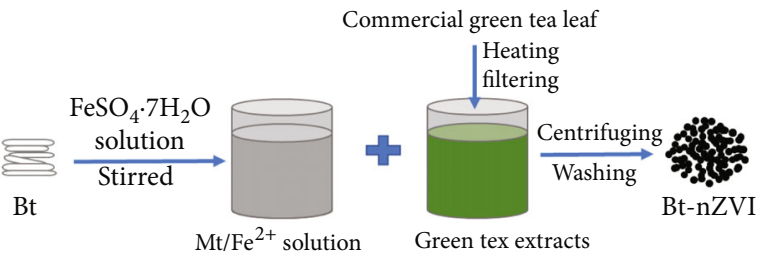

(c)

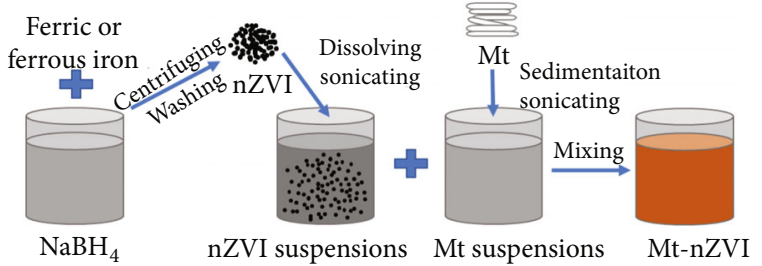

(b)

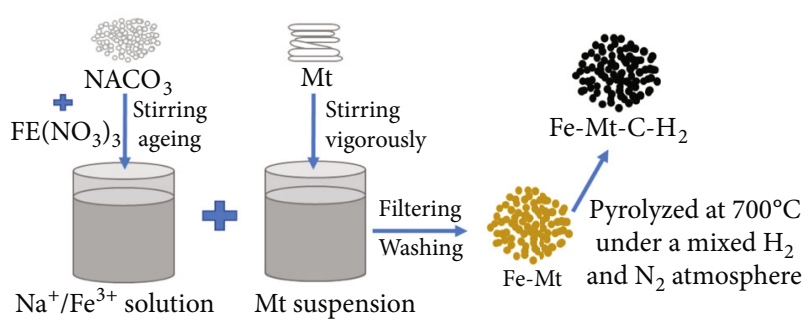

(d)

FIGURE 3: Illustration of the synthesis process of Mt-nZVI by different methods: (a) liquid-phase reduction; (b) heteroaggregates of Mt with nZVIs; (c) green synthesis method; (d) thermal reduction method.

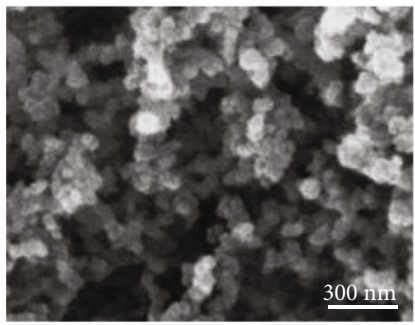

(a)

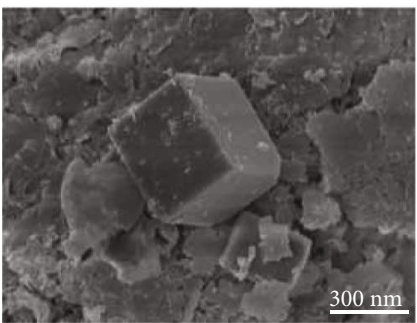

(d)

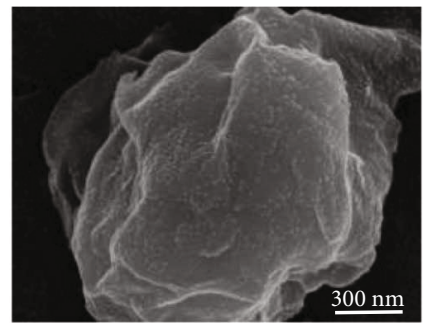

(b)

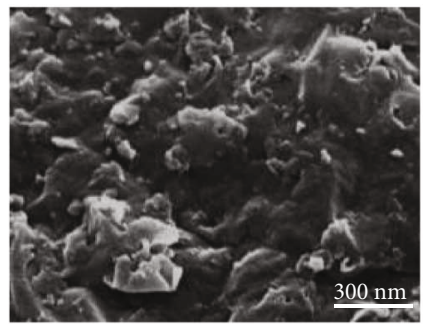

(e)

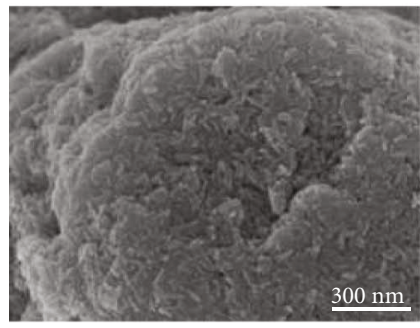

(c)

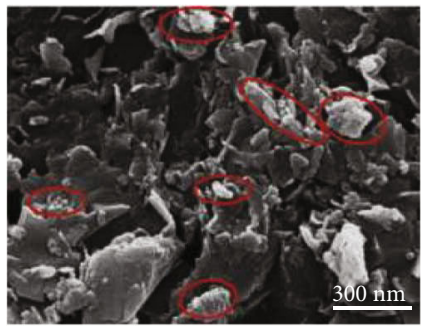

(f)

FIGURE 4: SEM images of (a) Bt-nZVI [51] synthesized by liquid-phase reduction and (b) heteroaggregates of Mt with nZVIs [15]. TEM images of (c) Bt and (d) Bt-supported "green" nZVI synthesized by green synthesis [60]. SEM images of (e) Fe-Mt and (f) Fe-Mt-H synthesized by thermal reduction method [64].

morphology of nZVI on the template surfaces influences the interaction energy between the composite and the collector surfaces and accordingly the attachment.

2.2.2. Heteroaggregates of $M t$ with $n Z V I s$. Yin et al. [15] presented a novel technique to prepare Mt-nZVI based on the liquid-phase reduction method. Specifically, nZVI colloidal suspension was first synthesized by the liquid-phase reduction reaction [54], and the nZVIs were allowed to attach to surfaces of $\mathrm{Mt}$ in solutions in a monolayer (Figure 3(b)). The Mt solution was prepared by sedimentation siphon separation [55]. The SEM images of Mt-nZVI synthesized by this method showed that the nZVI particles were evenly distributed on the Mt surfaces in a monolayer (Figure 4(b)) [15].

In this approach, the sizes of nZVI particles could be changed via the liquid-phase reduction method and the concentration of the attached nZVI particles on Mt could be controlled by varying experimental conditions (e.g., the ratio of concentrations of Mt and nZVI in suspension) [15]. The fabricated heteroaggregates of nZVIs with Mt had a unique micro/nanostructure. This structure favors the heteroaggregates to attach to collector surfaces and then detach even with a minor change of system conditions $[56,57]$. Therefore, the Mt-nZVI has great mobility in the subsurface 
environments through continuous capture and release, showing the promise for the in situ treatment of contaminants in soil [15]. Note that the previous method can also change the sizes of nZVI particles by changing experimental conditions.

2.2.3. Green Synthesis. The chemical synthesis methods of Mt-nZVI may lead to toxic chemicals (e.g., borohydride) absorbed on their surfaces [58]. Alternatively, the green synthesis method used plant extracts containing naturally derived polyphenolic compounds (instead of $\mathrm{NaBH}_{4}$ ) as reducing agents to synthesize Mt-nZVI [59]. For example, Soliemanzadeh and Fekri [60] used green tea extracts to prepare Bt-loaded "green" nZVI. The green tea extract solution was prepared by heating the plant extracts to a temperature close to the boiling point, and then it was mixed with the $\mathrm{Bt}$ and $\mathrm{Fe}^{2+}$ solution (Figure 3(c)). The transmission electron microscope (TEM) images (Figures 4(e) and 4(f)) indicated that nZVIs were successfully supported on the Bt surface. Moreover, the composite material prepared by this method was found to be effective for the adsorption of $\mathrm{Cr}(\mathrm{VI})$ in contaminated soil and aqueous environments.

The green synthesis method has the following advantages. First, plant extracts can better stabilize the reaction surface of nanoparticles than $\mathrm{NaBH}_{4}$ and decrease their biotoxicity [52]. Second, excess polyphenols in solution during preparation could encapsulate the synthesized Mt-nZVI and prevent its further oxidation [58]. Third, the use of natural active biological components can reduce the total cost of the synthesis process [61]. However, it should be noted that plant extracts may not completely reduce iron to nZVI, resulting in other forms of iron on template surfaces. Moreover, the preparation method of "green" extracts is relatively complicated, and the disposal of residues after extraction needs to be addressed [62]. These limitations decrease the application of green synthesis [28].

2.2.4. Thermal Reduction Method. Mt-nZVI can also be obtained through the thermal reduction of iron compounds [28]. In this method, the thermal energy and gaseous reducing agents were adopted to drive the reduction of iron oxide or hydrous $\mathrm{Fe}^{2+}$ at elevated temperatures in the presence of $\mathrm{Mt}$ [63]. For instance, Yang et al. [64] added an aqueous dispersion of $\mathrm{Mt}$ to the mixture of ferric nitrate and sodium carbonate to synthesize iron-pillared $\mathrm{Mt}$ (Fe-Mt) [65] and obtained $\mathrm{Fe}^{0}-\mathrm{Mt}$ composites (Fe-Mt$\mathrm{H}_{2}$ ) through thermal reduction under mixed $\mathrm{H}_{2}$ and $\mathrm{N}_{2}$ atmosphere (Figure 3(d)). The SEM images of Fe-Mt showed that small needle-like Fe particles attached to the surface of Mt (Figure 4(e)). With high-temperature pyrolysis, small needle-like protrusions distributed on the Mt surfaces partially turned into large cube-like particles (Figure 4(f)). Compared with Mt-nZVI prepared by the aforementioned liquidphase reduction, $\mathrm{Fe}-\mathrm{Mt}-\mathrm{H}_{2}$ embedded more $\mathrm{Fe}^{0}$ in $\mathrm{Mt}$ with larger sizes, which might be more difficult to be oxidized.

The thermal reduction method is cheaper and energysaving because it does not require $\mathrm{NaBH}_{4}$ for $\mathrm{Fe}$ ion reduction compared to the liquid-phase reduction method. The production of toxic chemicals is also avoided [12].
The method is also environmentally friendly because only gaseous products are generated [28]. However, this method requires high-temperature conditions, which is energyconsuming and may bring potential risks during the preparation [31].

Although the cost of producing Mt-nZVI has been reduced, large-scale preparation and application are still expensive. Further improvement is thus necessary to produce high-quality, low-cost, and environmentally friendly MtnZVI. For example, it is vital to develop some cheap and environmentally friendly reducing agents to replace $\mathrm{NaBH}_{4}$. Additionally, different modifying agents can be used to introduce various functional groups into the Mt interlayer to increase Mt-nZVI's adsorption activity to target contaminants [66].

2.3. Advantages of Using Mt to Support $n Z V I$. The clay minerals are nontoxic, low cost, and environmentally friendly. Moreover, they have a high surface area and adsorption ability $[67,68]$. A number of studies demonstrated that the adsorption capacity of Mt was stronger than that of other clay minerals [69-71]. Furthermore, the combination of Mt and nZVI can result in a synergetic effect between adsorption by the Mt and removal by nZVI particles [31]. There are several advantages of using Mt to support nZVI, such as improvement of the dispersion and mobility and reduction of the particle size and oxidation tendency [21, 26]. These advantages will be elaborated on in detail in the following.

2.3.1. Increased Dispersion. Typically, the bare nZVI particles were spherical and formed prominent chainlike aggregates; adding Mt into nZVI can improve the dispersibility of nZVI [19]. Several possible reasons have been used to explain the increased dispersion of nZVI in Mt. First, during the preparation of the Mt-nZVI, $\mathrm{Fe}^{3+}\left(\right.$ or $\left.\mathrm{Fe}^{2+}\right)$ is uniformly absorbed into the interlayer of Mt through ion exchange [19]. This can control the nucleation of nZVI clusters produced by the reduction of $\mathrm{Fe}^{3+}$ (or $\mathrm{Fe}^{2+}$ ) and limit the growth of particles, thereby preventing the aggregation of nZVI clusters [72]. Second, the interlaminar distance (between clay sheets) of Mt clay is between 0.1 and $0.8 \mathrm{~nm}$, which creates an ideal template to carry nZVI clusters (Figure 2) [18]. Adding nZVI into $\mathrm{Mt}$ can increase its interlayer spacing. The basal spacing of Mt-nZVI calculated by Pang et al. [73] was $2.450 \mathrm{~nm}$, which was $0.571 \mathrm{~nm}$ larger than that of Mt. This phenomenon might be explained by the fact that the hydration radius of $\mathrm{Fe}^{3+}$ was much larger than that of $\mathrm{Na}^{+}$, and when $\mathrm{Na}^{+}$was replaced by $\mathrm{Fe}^{3+}$, the interlayer spacing of $\mathrm{Mt}$ was increased. In short, the nZVI clusters have intercalated the interlayers of Mt and acted as pillars, thus expanding the interlayer distance. In addition, the surface area of $\mathrm{Mt}$ is much larger than that of nZVI, which can significantly increase the surface dispersion of nZVI [21]. Third, as a 2:1 layer silicate due to the swelling of the interlayer, the layers in Mt are separated into discrete single-layer units, which make Mt highly accessible in the suspension to some extent, thereby enhancing the reactivity of Mt-nZVI [72, 74]. Notably, the nZVI aggregation decreased as Mt loadings increased [22, 68, 75]. 


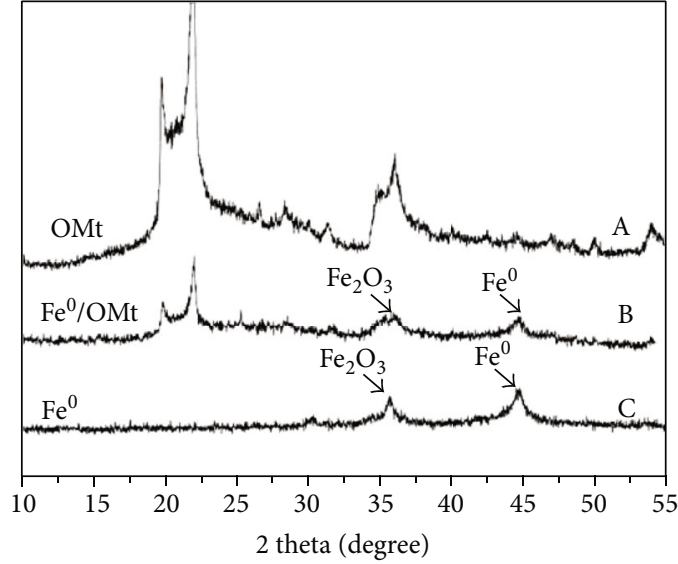

(a)

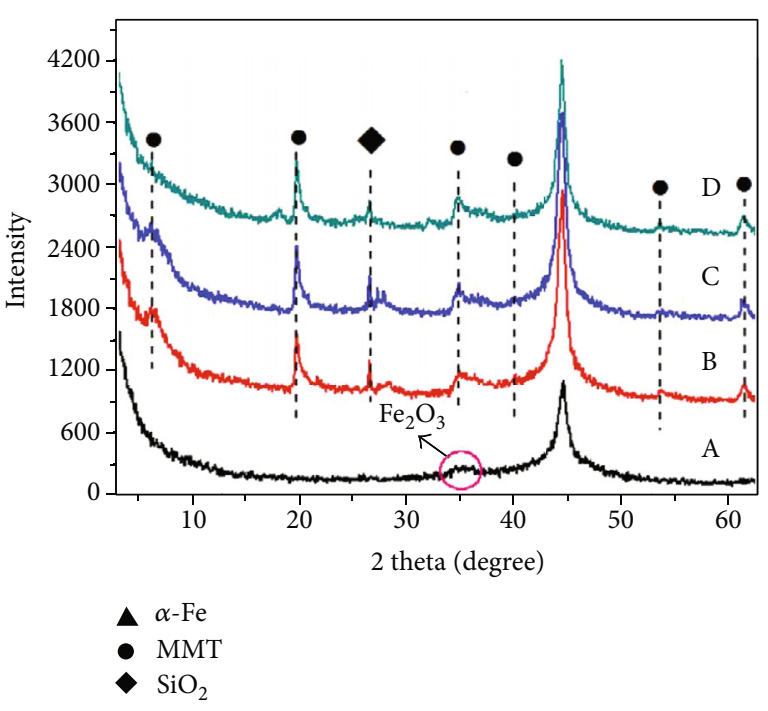

(b)

Figure 5: XRD patterns of (a) (A) OMt, (B) OMt-nZVI, and (C) nZVI [26] and (b) (A) nZVI, (B) Mt-nZVI, (C) K-Mt-supported nZVI (K-Mt-nZVI), and (D) starch-stabilized K-Mt-nZVI [21].

2.3.2. Small $n Z V I$ Size. The presence of templates such as $\mathrm{Mt}$ or Bt can reduce particle sizes of nZVI [76]. For example, Arancibia-Miranda et al. [77] found that the average diameter of Mt-nZVI was $9.3 \mathrm{~nm}$, which was smaller than that of nZVI $(16.9 \mathrm{~nm})$. The X-ray diffraction (XRD) patterns from Peng et al. [26] have shown that the peak value of the organo-Mt- (OMt-) supported nZVI (OMt-nZVI) was weaker and broader at $44.78^{\circ}$ compared with that of bare nZVI (Figure 5(a)), indicating the smaller crystallite size of nZVI within OMt-nZVI. The sizes of nZVI can be further decreased with the increase of the mass ratios of $\mathrm{Mt}$ /iron [68, 75, 76].

Smaller size of nZVI means larger SSA and stronger adsorption capacity [34]. Compared with Mt, the SSA of Mt-nZVI is increased as a result of massive nZVI particles supported on the surface or interlayers of $\mathrm{Mt}[24,36]$. Although the SSA of Mt-nZVI is lower than that of nZVI, the stability and reactivity of nZVI are stronger after being monodispersed on Mt [68].

2.3.3. Improved nZVI's Stability against Oxidization. The nZVI is easily oxidized when exposed to the air, which greatly affects its reducibility [72]. Mt can reduce the surface corrosion of nZVI and improve its stability [12]. According to the XRD results of Mt-nZVI by Zhang et al. [21] (Figure 5(b)), the characteristic peaks of iron oxide were not observed, indicating that the nZVI particles were not oxidized or only a small part of them was oxidized to form amorphous iron oxide. Rao et al. [78] investigated the antioxidant abilities of Mt-nZVI and nZVI by observing their color changes in the air at different time slots. The black nZVI solution totally turned yellow at $72 \mathrm{~h}$, while only a small part of the Mt-nZVI solution turned yellow, revealing that nZVI loaded on $\mathrm{Mt}$ was more difficult to be oxidized compared to pristine nZVI. This phenomenon can be explained by the fact that Mt has a layered structure, and when the nZVIs are inserted in the interlayer of $\mathrm{Mt}$, they were not readily available for oxidization [25].

Li et al. [79] found that fewer oxides were formed on BtnZVI compared to nZVI. The removal efficiency of Se(VI) by Bt-nZVI only decreased $3.7 \%$ after four cycle experiments. The results indicated that Bt-nZVI displayed much higher stability and reusability than nZVI, which was partly due to the fact that Bt inhibited the oxidation of nZVI. Another possible reason was the buffering effect of some particular functional groups of $\mathrm{Bt}$ [79]. Moreover, when $\mathrm{Fe}_{2} \mathrm{O}_{3}$ was formed and precipitated on the surfaces of $\mathrm{nZVI}$ during the reaction of Bt-nZVI with contaminants, Bt could help to transfer some precipitates from nZVI surfaces and prolong the reactivity of nZVI [65].

2.3.4. Other Advantages. Tomasevic et al. [67] and Kerkez et al. [69] demonstrated that the total pore volume of the Mt-nZVI was larger than that of Mt and nZVI. This is because of the formation of more mesoporous structures by the intercalated nZVI, which enhanced the diffusion and adsorption of contaminants [26]. In addition, the introduction of Mt may improve the sustainability of nZVI, inhibit the rapid consumption of nZVI, and ultimately enhance the service life of composite materials [19]. Finally, Bt-nZVI has higher stability (lower sedimentation) and greater mobility in porous media than nZVI [80]. For example, Shi et al. [68] conducted column experiments and revealed that the sedimentation rate of Mt-nZVI was greatly decreased and its mobility was significantly increased compared with that of bare nZVI. This is because the zeta potentials of nZVI particles changed from positive to negative after the addition of $\mathrm{Mt}$, which led to the repulsive interaction between Bt-nZVI and quartz sand [80]. 


\section{The Reaction Mechanisms of Mt-nZVI}

There are four typical pathways to remove contaminants by Mt-nZVI (Figure 6), including adsorption [19, 81, 82], reduction $[18,26,83]$, precipitation $[16,21]$, and oxidation [44]. These mechanisms can occur simultaneously or sequentially when using them to remove contaminants. Particularly, adsorption is commonly the major removal mechanism for $\mathrm{Mt}$, while reduction is the main mechanism for the nZVI $[18,19]$. These processes are described in detail in the following.

Adsorption has been considered a typical reaction process for contaminant removal by Mt-nZVI. As mentioned above, Mt-nZVI has small particle sizes, large SSA, and abundant active sites due to functional groups, which have a great ability for adsorbing many contaminants [15]. Additionally, nZVI has a core-shell structure (Figure 6). Specifically, the core is mainly nZVI, and the shell is the product due to oxidation of the nZVI. The shell can be oxidized to $\mathrm{Fe}^{2+}$ (fast process) and further to $\mathrm{Fe}^{3+}$ (slower process) by dissolved oxygen in aqueous media according to Equations (3) and (4) [30]:

$$
\begin{aligned}
& 2 \mathrm{Fe}^{0}+\mathrm{O}_{2}+2 \mathrm{H}_{2} \mathrm{O} \longrightarrow 2 \mathrm{Fe}^{2+}+4 \mathrm{OH}^{-} \\
& 4 \mathrm{Fe}^{2+}+\mathrm{O}_{2}+4 \mathrm{H}^{+} \longrightarrow 4 \mathrm{Fe}^{3+}+2 \mathrm{H}_{2} \mathrm{O}
\end{aligned}
$$

The outer oxidized layer of nZVI will thicken once exposed in water or air even if this process is reduced due to the Mt. This positively charged layer can act as an efficient adsorbent for various contaminants with negative charges through electrostatic interaction [27]. Reduction was regarded to be the main mechanism of contaminant removal by Mt-nZVI, in which nZVI plays as an electron provider $[33,84]$. Generally speaking, the removal mechanisms of Mt-nZVI on heavy metals depend on its $E^{0}$ (Table 3) [29]. The heavy metals with more positive standard redox potential $\left(E^{0}\right)$ than nZVI $\left(E^{0}=-0.44 \mathrm{~V}\right)$ such as $\mathrm{Pb}(\mathrm{II})$ and $\mathrm{Ni}(\mathrm{II})$ can be removed by reduction and adsorption [85]. For example, Wang et al. [34] showed that Mt-nZVI could remove $\mathrm{Pb}(\mathrm{II})$ to $\mathrm{Pb}^{0}$ by reduction and adsorption. First, $\mathrm{Pb}(\mathrm{II})$ ions were absorbed on the surface of Mt-nZVI (Equations (5) and (6)). Then, it was converted to $\mathrm{Pb}^{0}$ through reduction by nZVI (Equation (7)) [34]:

$$
\begin{gathered}
\mathrm{Pb}^{2+}+\mathrm{Mt} \longrightarrow \mathrm{Pb}^{2+}-\mathrm{Mt} \\
\mathrm{Pb}^{2+}+\mathrm{Fe}_{x} \mathrm{O}_{y} \mathrm{H}_{z} \longrightarrow \mathrm{Pb}^{2+}-\mathrm{Fe}_{x} \mathrm{O}_{y} \mathrm{H}_{z} \\
\mathrm{~Pb}^{2+}-\mathrm{Mt}\left(\text { or } \mathrm{Pb}^{2+}-\mathrm{Fe}_{x} \mathrm{O}_{y} \mathrm{H}_{z}\right)+2 \mathrm{e}^{-} \\
\longrightarrow \mathrm{Pb}^{0}-\mathrm{Mt}\left(\text { or } \mathrm{Pb}^{0}-\mathrm{Fe}_{x} \mathrm{O}_{y} \mathrm{H}_{z}\right)
\end{gathered}
$$

When the $E^{0}$ of the compound is smaller or similar to that of nZVI, Mt-nZVI removes it purely by adsorption. For example, due to the fact that $E^{0}$ of $\mathrm{Zn}$ (II) is much smaller than that of nZVI, $\mathrm{Fe}^{0}$ cannot reduce it into $\mathrm{Zn}^{0}$, but it is absorbed and deposited on the Mt-nZVI in the form of $\mathrm{Zn}(\mathrm{II})[53,68,81]$. In contrast, the reduction reaction of Mt-nZVI occurs for heavy metals with higher $E^{0}$ (e.g., $\mathrm{Cr}(\mathrm{VI})$

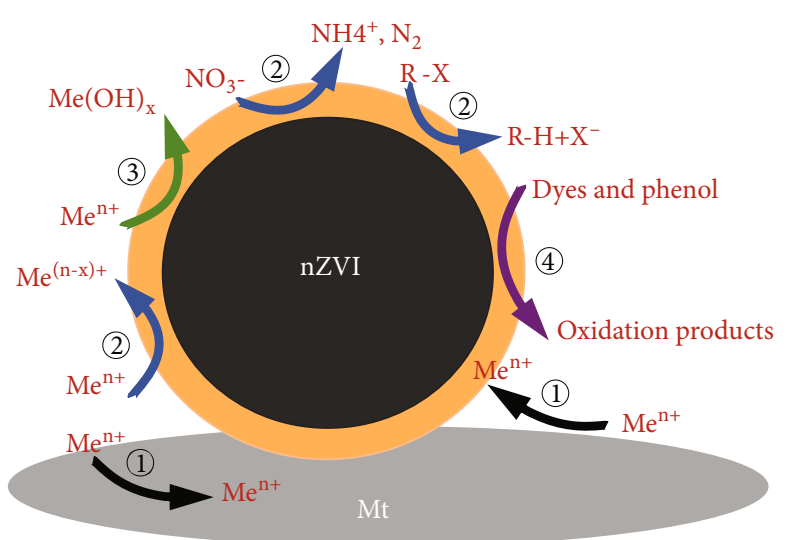

FIgURE 6: Schematic model of reaction mechanisms of Mt-nZVI with various contaminants.

is preferentially reduced in the presence of nZVI) [12]. Interestingly, Mt-nZVI can reduce nitrate to ammonium and nitrogen gas (Equations (8)-(10)) [86]:

$$
\begin{gathered}
\mathrm{Fe}^{0}+\mathrm{NO}_{3}{ }^{-}+2 \mathrm{H}^{+} \longrightarrow \mathrm{Fe}^{2+}+\mathrm{H}_{2} \mathrm{O}+\mathrm{NO}_{2}^{-} \\
3 \mathrm{Fe}^{0}+\mathrm{NO}_{2}{ }^{-}+8 \mathrm{H}^{+} \longrightarrow 3 \mathrm{Fe}^{2+}+2 \mathrm{H}_{2} \mathrm{O}+\mathrm{NH}_{4}{ }^{+} \\
3 \mathrm{Fe}^{0}+2 \mathrm{NO}_{2}{ }^{-}+8 \mathrm{H}^{+} \longrightarrow 3 \mathrm{Fe}^{2+}+4 \mathrm{H}_{2} \mathrm{O}+\mathrm{N}_{2}(\mathrm{~g})
\end{gathered}
$$

This means that Mt-nZVI may help to reduce the amount of total nitrogen in the water. Mt-nZVI can also provide electrons for the reduction of halogenated organics. The halogenated organics are reduced to the olefins and alkane by reductive dehalogenation (Equations (11) and (12)) [8]:

$$
\begin{aligned}
\mathrm{Fe}^{0} & \longrightarrow \mathrm{Fe}^{2+}+2 \mathrm{e}^{-} \\
\mathrm{R}-\mathrm{X}+\mathrm{H}^{+}+2 \mathrm{e}^{-} & \longrightarrow \mathrm{RH}+\mathrm{X}^{-}
\end{aligned}
$$

The reaction involves the adsorption of contaminants onto the Mt-nZVI surface and subsequent breakage of the carbon-halogen bonds [52]. Based on the reductive dehalogenation, Mt-nZVI could remove chlorinated and brominated organics [19, 31].

The precipitation mechanism may occur between heavy metals and iron ions. This can significantly decrease the toxicity and mobility of heavy metals since the formed precipitation is stable [87]. For instance, $\mathrm{Cr}(\mathrm{VI})$ can be removed by Mt-nZVI through adsorption, reduction, and precipitation $[16,36,43,81]$. The reaction includes (1) the adsorption of $\mathrm{Cr}(\mathrm{VI})$ on the surface of Mt-nZVI, (2) the reduction to $\mathrm{Cr}$ (III) with the oxidation of nZVI to $\mathrm{Fe}^{3+}$, and (3) the formation of chromium hydroxide or chromium iron hydroxide precipitation (Equations (13) and (14)):

$$
\begin{gathered}
\mathrm{Cr}_{2} \mathrm{O}_{7}^{2-}+2 \mathrm{Fe}^{0}+14 \mathrm{H}^{+} \longrightarrow 2 \mathrm{Cr}^{3+}+7 \mathrm{H}_{2} \mathrm{O}+2 \mathrm{Fe}^{3+} \\
\mathrm{Cr}^{3+}+\mathrm{Fe}^{3+}+6 \mathrm{OH}^{-} \longrightarrow \mathrm{Cr}(\mathrm{OH})_{3}+\mathrm{Fe}(\mathrm{OH})_{3}
\end{gathered}
$$

Mt-nZVI can also remove U(VI), Cu(II), Se(IV), and As $(\mathrm{V})$ through above processes $[25,33,82,88]$. In some 
TABLE 3: The standard redox potentials $\left(E^{0}\right)$ of heavy metals at $25^{\circ} \mathrm{C}$ [29].

\begin{tabular}{lcccc}
\hline Heavy metal & $E^{0}(\mathrm{~V})$ & Half reactions & Removal mechanism & Reference \\
\hline $\mathrm{Zn}$ & -0.76 & $\mathrm{Zn}^{2+} \leftrightarrow \mathrm{Zn}^{2+}$ & Adsorption & {$[68]$} \\
$\mathrm{Fe}$ & -0.44 & $\mathrm{Fe}^{2+}+2 \mathrm{e}^{-} \leftrightarrow \mathrm{Fe}$ & Reduction & {$[29]$} \\
$\mathrm{Ni}$ & -0.23 & $\mathrm{Ni}^{2+}+2 \mathrm{e}^{-} \leftrightarrow \mathrm{Ni}$ & Reduction and adsorption & {$[85]$} \\
$\mathrm{Pb}$ & -0.13 & $\mathrm{~Pb}^{2+}+2 \mathrm{e}^{-} \leftrightarrow \mathrm{Pb}$ & Reduction and adsorption & {$[108]$} \\
$\mathrm{U}$ & 0.27 & $\mathrm{UO}_{2}^{2+}+4 \mathrm{H}^{+}+2 \mathrm{e}^{-} \leftrightarrow \mathrm{U}^{4+}+2 \mathrm{H}_{2} \mathrm{O}$ & Reduction and precipitation & {$[25]$} \\
$\mathrm{Cu}$ & 0.34 & $\mathrm{Cu}^{2+}+2 \mathrm{e}^{-} \leftrightarrow \mathrm{Cu}$ & Reduction and precipitation & {$[88]$} \\
$\mathrm{As}$ & 0.56 & $\mathrm{H}_{3} \mathrm{AsO}_{4}+2 \mathrm{H}^{+}+2 \mathrm{e}^{-} \leftrightarrow \mathrm{HAsO}_{2}+2 \mathrm{H}_{2} \mathrm{O}$ & Reduction and precipitation & {$[76]$} \\
$\mathrm{Cr}$ & 1.36 & $\mathrm{Cr}_{2} \mathrm{O}_{7}^{2-}+14 \mathrm{H}^{+}+6 \mathrm{e}^{-} \leftrightarrow 2 \mathrm{Cr}^{3+}+7 \mathrm{H}_{2} \mathrm{O}$ & Reduction and precipitation & {$[16]$} \\
\hline
\end{tabular}

special environmental remediation systems (e.g., the $\mathrm{Fe}^{0}-$ $\mathrm{H}_{2} \mathrm{O}$ mixture system), oxidation is also a possible reaction mechanism. Mt-nZVI can degrade and oxidize a series of organic compounds in the presence of oxidants. For example, Diao et al. [22, 23] used Bt-nZVI as a catalyst to activate persulfate for the removal of phenol. The results indicated that the presence of persulfate in Bt-nZVI could significantly promote the oxidation of phenol. The reaction mechanisms include the following: (1) $\mathrm{SO}_{4}{ }^{2-}$ was formed by the reaction of aqueous $\mathrm{Fe}^{2+}$ with persulfate, and (2) phenol was degraded by $\mathrm{SO}_{4}{ }^{2-}$ and hydroxyl radicals $(\mathrm{OH})$. These processes can be described in the following equations:

$$
\begin{aligned}
2 \mathrm{Fe}^{0}+\mathrm{O}_{2}+4 \mathrm{H}^{+} & \longrightarrow 2 \mathrm{Fe}^{2+}+2 \mathrm{H}_{2} \mathrm{O} \\
\mathrm{Fe}^{2+}+\mathrm{S}_{2} \mathrm{O}_{8}{ }^{2-} & \longrightarrow \mathrm{Fe}^{3+}+\mathrm{SO}_{4}{ }^{-}+\mathrm{SO}_{4}{ }^{2-} \\
\mathrm{H}_{2} \mathrm{O}+\mathrm{SO}_{4}{ }^{-} & \longrightarrow \mathrm{HSO}_{4}{ }^{-}+{ }^{-} \mathrm{OH}
\end{aligned}
$$

Phenol $+\mathrm{SO}_{4}^{-}{ }^{-} \cdot \mathrm{OH} \longrightarrow$ oxidation product

Bao et al. [89] added $\mathrm{H}_{2} \mathrm{O}_{2}$ when using Mt-nZVI to remove bisphenol A. They found that the bisphenol A degradation mechanism might involve a couple of adsorption reactions with the Fenton-like reaction (e.g., a reaction system made up of $\mathrm{H}_{2} \mathrm{O}_{2}$ and $\mathrm{Fe}^{2+}$ ). The combination of $\mathrm{H}_{2} \mathrm{O}_{2}$ and $\mathrm{Fe}^{2+}$ could generate $\mathrm{OH}$, which had a strong capability to oxidize a variety of organic compounds (Equations (19) and (20)) [1]:

$$
\begin{aligned}
\mathrm{Fe}^{0}+\mathrm{H}_{2} \mathrm{O}_{2}+2 \mathrm{H}^{+} & \longrightarrow \mathrm{Fe}^{2+}+2 \mathrm{H}_{2} \mathrm{O} \\
\mathrm{Fe}^{2+}+\mathrm{H}_{2} \mathrm{O}_{2} & \longrightarrow \mathrm{Fe}^{3+}+{ }^{\circ} \mathrm{OH}+\mathrm{OH}^{-}
\end{aligned}
$$

Kerkez et al. [56] reported that the heterogeneous Fenton oxidation system was considerably superior in dye decolorization than the reduction degradation mechanism. Chen et al. [65] used Fe-pillared Mt as a heterogeneous photoFenton catalyst to enhance the degradation efficiency of dyes. However, under common natural environmental conditions, oxidation is rare for the removal of contaminants by MtnZVI [90].

The synergistic effect between nZVI and Mt on the removal of many contaminants has been reported [50,79]. For example, the removal efficiency of Mt-nZVI for Cr(VI)
(99\%) is even better than the sum (72\%) of individual removal efficiency of nZVI and Mt (66\% and 6\%, respectively) [81]. The synergistic effect is due to several reasons. First, as mentioned previously, the Mt can decrease the size of nZVI and enhance the dispersity of nZVI, thus providing more effective electron donors and active sites [18]. Second, the Mt of Mt-nZVI can facilitate the capture of contaminants from the solution on the Mt-nZVI surfaces through exchange and adsorption due to its high cation exchange capacity and SSA [50]. For example, the negatively charged Mt can attract cationic contaminants (such as $\mathrm{Pb}, \mathrm{Cd}$, and $\mathrm{Cu}$ ) via electrostatic attraction and promote the mass transfer of these contaminants from the solution to the nZVI surface, thereby improving the removal efficiency [33]. Third, the $\mathrm{pH}$ buffering effect of silanol groups in the Mt may also promote the synergetic effect of $\mathrm{Mt}$ on the reduction of contaminants by nZVI [79]. Finally, the interlayer of raw Mt can be modified by cation exchange reaction. Therefore, the surface and structure of Mt can be adjusted to create properties compatible with various contaminants [33], which will be discussed in Section 5.

\section{Factors Affecting Mt-nZVI Reactivity}

When applying Mt-nZVI for water and soil remediation, the reactivity of Mt-nZVI with contaminants is dependent on a variety of environmental conditions (e.g., $\mathrm{pH}$, temperature, and dosage of the adsorbent). The impact of environmental factors on the removal of contaminants by Mt-nZVI is frequently examined using experimental methods such as batch and column techniques [15]. Understanding the impact of environmental conditions is critical to optimizing the procedure for the removal of contaminants via Mt-nZVI.

4.1. $p H$. The $\mathrm{pH}$ value can change the surface properties of Mt-nZVI and species of the molecules or irons, thereby affecting the removal efficiency [90]. First, the surface equipotential point of Mt-nZVI and accordingly the affinity for contaminants change with $\mathrm{pH}$ [47]. When Mt is dispersed in the aqueous solution, the $\mathrm{Si}-\mathrm{O}$ and $\mathrm{Al}-\mathrm{O}$ bonds in the crystal lattice can be broken [50]. When the aqueous solution is acidic, the broken bond will adsorb $\mathrm{H}^{+}$ions, resulting in positive charges of the crystal lattice. In contrast, the bond is adsorbed by the $\mathrm{OH}^{-}$and the lattice is negatively charged 
under alkaline conditions [80, 83]. Hence, Mt-nZVI has a stronger adsorption capacity for cationic contaminants at higher pH values (e.g., Co(II) [49], U(VI) [25], Zn(II) [53], and $\mathrm{Pb}(\mathrm{II})[50,77])$. In addition, nZVI in the solution will form a passive film of iron hydroxide at a higher $\mathrm{pH}$ value, further enhancing the adsorption of cationic contaminants [36]. At a low $\mathrm{pH}$ value, Mt-nZVI has a stronger adsorption capacity for anionic contaminants (e.g., $\mathrm{Cr}(\mathrm{VI})[43,53,80]$, phenol [22, 89], halogenated organic contaminants [42, 73], nitrobenzene [70], and acid dyestuff $[24,69,74,78])$. More $\mathrm{H}^{+}$can promote the reaction and consume more nZVIs, and the nZVI corrosion produces abundant hydrogen at lower $\mathrm{pH}$ values, which may support the hydrogenation reaction between organic compounds and hydrogen [45]. Notably, the $\mathrm{pH}$ not only changes properties of Mt-nZVI but also affects the charges of target contaminants (e.g., $\mathrm{HCrO}_{4}{ }^{-}$ $(\mathrm{pH}=2-5), \mathrm{Cr}_{2} \mathrm{O}_{7}{ }^{2-}$ or $\left.\mathrm{CrO}_{4}{ }^{2-}(\mathrm{pH}>5)\right)[62]$.

4.2. Temperature. Temperature can change the energy of the reaction system, thus influencing contaminant removal efficiency by Mt-nZVI [90]. For example, Shi et al. [81] found that $82.4 \%$ of $\mathrm{Cr}(\mathrm{VI})$ was removed by $\mathrm{Mt}-\mathrm{nZVI}$ at $40^{\circ} \mathrm{C}$, while only $73.4 \%$ of $\mathrm{Cr}(\mathrm{VI})$ was reduced at $25^{\circ} \mathrm{C}$ in $60 \mathrm{~min}$. A possible explanation was that high temperature could facilitate the molecular thermodynamic movement and average kinetic energy of contaminants [46]. The increase in the removal efficiency with increasing temperature was observed for degradation of organic contaminants, such as sulfamethazine [44], methyl orange [24], and amoxicillin [91] by OMtnZVI. Overall, increasing temperature has a positive effect on the ability of Mt-nZVI to adsorb contaminants, which favors in situ remediations of the environment.

The thermodynamic parameters (e.g., change in free energy $(\Delta G)$, enthalpy change $(\Delta H)$, and change in entropy $(\Delta S)$ ) can reveal the reaction mechanisms [92]. For example, the thermodynamic study by Wang [92] demonstrated that the adsorption of rare earth elements by Mt-nZVI was spontaneous based on the negative $\Delta G$ values and exothermic since the value of $\Delta H$ was negative. In addition, the randomness of the system after adsorption was decreased (negative value of $\Delta S$ ). Moreover, the adsorption reaction of $\mathrm{Pb}$ (II) and $\mathrm{Cr}(\mathrm{VI})$ on Mt-nZVI was spontaneous $(\Delta G<0)$ and exothermic $(\Delta H<0)[15,34]$.

4.3. Dosage of the Adsorbent. The dosage of Mt-nZVI has a significant impact on the removal of contaminants. Shi et al. [51] presented that the removal efficiency of $\mathrm{Cr}(\mathrm{VI})$ by $3 \mathrm{~g} \mathrm{~L}^{-1}$ of M-nZVI was $100 \%$ after contacting for $3 \mathrm{~h}$ at pH 5, while only $54.6 \% \mathrm{Cr}(\mathrm{VI})$ was removed when Bt-nZVI concentration was $1 \mathrm{gL}^{-1}$. This observation could be explained by the fact that for a given condition, the increase in the dosage of Mt-nZVI increased the surface area and adsorption sites of Mt-nZVI, which promoted the reduction of contaminants [50, 60, 91, 93-95]. Using an optimum dosage of the adsorbent is also of great significance for saving application costs [90].

Wu et al. [44] observed that the sulfamethazine degradation increased from $58 \%$ to $97 \%$ with 10 min interaction when the OMt-nZVI dose increased from $0.15 \mathrm{mM}$ to
$1.5 \mathrm{mM}$. However, if the OMt-nZVI further increased from $1.5 \mathrm{mM}$ to $12 \mathrm{mM}$, the degradation of sulfamethazine was reduced from $97 \%$ to $35 \%$. Similarly, when the dose of BtnZVI exceeded $2 \mathrm{gL}^{-1}$, the removal efficiency of chemical oxygen decreased slightly in wastewater [96]. This is likely because more Mt-nZVI dosage would induce greater aggregation of the Mt-nZVI, causing the decrease of the SSA and its dispersibility [22, 69].

4.4. Other Factors. The initial concentration of contaminants influences the relative adsorption sites of Mt-nZVI [16, 32, $74,83]$. Dissolved oxygen controls the adsorption capacity of Mt-nZVI by controlling the oxidation degree of nZVI particles $[24,73]$. In addition to these factors, inorganic anions [44], reaction time [73], ionic strength [16, 32, 60], natural organic matter (e.g., humic acid), and other ions [67] have an influence on the activity of Mt-nZVI. However, due to the complexity of soil and water environments, the factors that influence the removal of contaminants by Mt-nZVI are not fully elucidated to date. Hence, further research is still necessary to identify the impact factors and to reveal the coupled influence of these factors on the removal of the contaminants in soil and water environments.

\section{Remediation of Contaminated Water and Soil}

\subsection{Remediation of Contaminated Water}

5.1.1. Heavy Metals. Heavy metals enter the environment mainly through industrial production. They are difficult to be biodegraded and tend to accumulate in living organisms, thus posing a high potential risk to the ecosystem and human body [32]. Mt-nZVI has been applied to successfully remove heavy metals such as $\mathrm{Pb}(\mathrm{II}), \mathrm{Zn}(\mathrm{II}), \mathrm{Cu}(\mathrm{II})$, and particularly $\mathrm{Cr}(\mathrm{VI})$ in laboratory studies (Table 2).

Yin et al. [15] examined the removal of Cr(VI) by MtnZVI. They found that the adsorption data was well described by the Langmuir model and pseudo-second-order kinetics (Table 4). The $\mathrm{Cr}(\mathrm{VI})$ was retained on the MtnZVI surface in a monolayer through chemical adsorption [60]. However, Shi et al. [51] showed that the removal of $\mathrm{Cr}(\mathrm{VI})$ by Bt-nZVI followed pseudo-first-order reaction kinetics. To improve the removal efficiency of $\mathrm{Cr}(\mathrm{VI})$ by Mt-nZVI, Mt or nZVI was modified [43, 95]. For example, $\mathrm{Wu}$ et al. [43] reported better removal capacity for $\mathrm{Cr}(\mathrm{VI})$ $\left(109.9 \mathrm{mg} \mathrm{g}^{-1}\right)$ by HDTMA-modified Mt-supported nZVI compared to Mt-nZVI (90.9 $\mathrm{mg} \mathrm{g}^{-1}$ ) (Table 2). Wang et al. [95] fabricated Bt-supported organosolv lignin-stabilized nZVI and found that lignin could improve the loaded quantity and dispersity of nZVI. The $\mathrm{Cr}(\mathrm{VI})$ removal efficiency could reach $62.3 \%$ when the dosage of this fabricated structure was $1.0 \mathrm{gL}^{-1}$ and initial $\mathrm{Cr}(\mathrm{VI})$ concentration was $50 \mathrm{mg} \mathrm{L}^{-1}$, which was higher than that of Bt-nZVI (56.8\%).

Arancibia-Miranda et al. [77] observed that the maximum $\mathrm{Pb}$ (II) adsorption capacity on Mt-nZVI was $115.1 \pm$ $11.0 \mathrm{mg} \mathrm{g}^{-1}$, and the reaction followed the pseudo-secondorder kinetic model and the Langmuir model. Wang et al. [34] examined the adsorption of $\mathrm{Zn}$ (II) and $\mathrm{Pb}$ (II) by MtnZVI. The adsorption data of $\mathrm{Zn}$ (II) followed the Freundlich, 
TABLE 4: Fitting results for the adsorption kinetic and isotherm models of contaminant removal by Mt-nZVI.

\begin{tabular}{|c|c|c|c|c|}
\hline Material & Contaminants & $\begin{array}{l}\text { Adsorption kinetic } \\
\text { model }\end{array}$ & $\begin{array}{l}\text { Adsorption isotherm } \\
\text { model }\end{array}$ & Reference \\
\hline$\overline{M t-n Z V I}$ & $\mathrm{Cr}(\mathrm{VI})$ & Pseudo-second-order & Langmuir & {$[15]$} \\
\hline OMt-nZVI & $\mathrm{Cr}(\mathrm{VI})$ & Pseudo-second-order & - & {$[43]$} \\
\hline Bt-nZVI & $\mathrm{Cr}(\mathrm{VI})$ & Pseudo-first-order & - & {$[51]$} \\
\hline Bt-nZVI & $\mathrm{Cr}(\mathrm{VI})$ & Pseudo-second-order & Langmuir & {$[60]$} \\
\hline Mt-nZVI & $\mathrm{Pb}(\mathrm{II})$ & Pseudo-second-order & Langmuir & {$[77]$} \\
\hline \multirow[b]{2}{*}{ Mt-nZVI } & $\mathrm{Pb}(\mathrm{II})$ & Pseudo-second-order & Freundlich & \multirow[b]{2}{*}[34]{} \\
\hline & $\mathrm{Zn}(\mathrm{II})$ & Pseudo-second-order & $\begin{array}{l}\text { Freundlich, Temkin, and } \\
\text { Dubinin-Radushkevich }\end{array}$ & \\
\hline Bt-nZVI & $\mathrm{Cu}(\mathrm{II})$ and $\mathrm{Zn}(\mathrm{II})$ & Pseudo-first-order & - & {$[68]$} \\
\hline Bt/graphene-supported nZVI & $\mathrm{Cu}(\mathrm{II})$ & Pseudo-second-order & - & {$[88]$} \\
\hline Bt-nZVI & $\mathrm{U}(\mathrm{VI})$ & Langmuir-Hinshelwood & - & {$[25]$} \\
\hline Mt-nZVI & $\mathrm{U}(\mathrm{VI})$ & & Langmuir & {$[71]$} \\
\hline Pillared Bt-supported nZVI & $\mathrm{NO}_{3}^{-}$ & Langmuir-Hinshelwood & - & {$[86]$} \\
\hline $\begin{array}{l}\text { Cetyltrimethylammonium bromide-modified } \\
\text { Mt-supported nZVI }\end{array}$ & $\begin{array}{l}\text { Decabromodiphenyl } \\
\text { ether }\end{array}$ & Pseudo-first-order & - & {$[73]$} \\
\hline $\begin{array}{l}\text { Cetyltrimethylammonium-modified } \\
\text { Bt-supported nZVI }\end{array}$ & Chlorophenols & Langmuir-Hinshelwood & Langmuir & {$[66]$} \\
\hline $\begin{array}{l}\text { Cetyltrimethylammonium-modified } \\
\text { Bt-supported nZVI }\end{array}$ & Pentachlorophenol & Langmuir-Hinshelwood & - & {$[40]$} \\
\hline Bt-nZVI & Acid violet red B & Pseudo-first-order & - & {$[74]$} \\
\hline Bt-nZVI & Methyl orange & Pseudo-first-order & - & {$[24]$} \\
\hline Mt-nZVI & Rhodamine 6G & Pseudo-first-order & - & {$[78]$} \\
\hline Bt-nZVI & $\mathrm{Se}(\mathrm{VI})$ & Langmuir-Hinshelwood & - & {$[79]$} \\
\hline \multirow{2}{*}{ Mt-nZVI } & $\mathrm{Se}(\mathrm{VI})$ & Pseudo-first-order & Freundlich & \multirow{2}{*}[76]{} \\
\hline & $\operatorname{As}(\mathrm{V})$ & Pseudo-second-order & Freundlich & \\
\hline $\begin{array}{l}\text { Cetyltrimethylammonium-modified } \\
\text { Bt-supported nZVI }\end{array}$ & Nitrobenzene & Langmuir-Hinshelwood & - & {$[41]$} \\
\hline
\end{tabular}

Temkin, and Dubinin-Radushkevich isotherm models, meaning the copresence of physical and chemical adsorption. $\mathrm{The} \mathrm{Pb}(\mathrm{II})$ adsorption process was chemisorption, and the reaction data was described by the Freundlich isotherm model. Shao et al. [88] presented that the removal efficiency of $\mathrm{Cu}(\mathrm{II})\left(C_{0}=100 \mathrm{mg} \mathrm{L}^{-1}\right)$ was $82 \%$ in Bt- and graphene oxide-supported nZVIs $\left(1 \mathrm{~g} \mathrm{~L}^{-1}\right)$ within $16 \mathrm{~h}$. The adsorption data followed the pseudo-second-order kinetic model.

The applications of Mt-nZVI for the treatment of industrial wastewater have been reported. For example, Shi et al. [68] used Bt-nZVI to remediate electroplating wastewater and found that $100 \% \mathrm{~Pb}(\mathrm{II}), 92.7 \% \mathrm{Cu}(\mathrm{II})$, and $59.4 \% \mathrm{Zn}(\mathrm{II})$ were removed within $1 \mathrm{~h}$ by $10 \mathrm{gL}^{-1} \mathrm{Bt}-\mathrm{nZVI}$. Wang et al. [97] studied the remediation effect of Bt-nZVI on leachate wastewater originating from $\mathrm{Cr}$-polluted soil. The results indicated that $90 \% \mathrm{Cr}(\mathrm{VI})$ from leachate wastewater with an initial concentration of $52.89 \mathrm{mg} \mathrm{L}^{-1} \mathrm{Cr}(\mathrm{VI})$ could be removed within $10 \mathrm{~min}$ using $3 \mathrm{mg} \mathrm{g}^{-1}$ of Bt-nZVI.

5.1.2. Uranium. $\mathrm{U}(\mathrm{VI})$, as a radioactive and toxic heavy metal, has relatively high solubility and mobility in the environment. Therefore, it readily invades the food chain [93]. Previous laboratory work demonstrated that soluble uranium compounds could be removed by using Mt-nZVI to reduce
U(VI) to less-soluble U(IV) [25, 32, 33]. For example, Sheng et al. [25] revealed that the adsorption data of U(VI) on BtnZVI followed the Langmuir-Hinshelwood model, and the removal efficiency of $\mathrm{U}(\mathrm{VI})\left(100 \mathrm{mg} \mathrm{L}^{-1}\right)$ reached $99.2 \%$ after $90 \mathrm{~min}$ when using $0.2 \mathrm{~g} \mathrm{~L}^{-1} \mathrm{Bt}-\mathrm{nZVI}$. Kornilovych et al. [71] used clay (e.g., kaolinite, Mt, and palygorskite)-supported nZVI to remove U(VI) from mineralized groundwater. They found that the adsorption process was better described by the Langmuir model. Mt-nZVI had the highest adsorption capacity (about $120 \mathrm{mgg}^{-1}$ ), which might be related to the high dispersibility of the Mt sample in the aqueous solution. $\mathrm{Xu}$ et al. [32] reported $97.8 \% \mathrm{U}(\mathrm{VI})\left(100 \mathrm{mg} \mathrm{L}^{-1}\right)$ removal by Mt-nZVI $\left(0.1 \mathrm{~g} \mathrm{~L}^{-1}\right)$ within $30 \mathrm{~min}$ at $\mathrm{pH}=3.0$. The aforementioned work indicated that Mt-nZVI was suitable for the removal of $\mathrm{U}(\mathrm{VI})$ from the aqueous solution.

5.1.3. Nitrate. Nitrate $\left(\mathrm{NO}_{3}{ }^{-}\right)$is widely presented in the surface and groundwater due to the widespread use of nitrogen fertilizers and improper treatment of industrial wastewater, causing deterioration of water quality, eutrophication of rivers, and toxicities to organisms [98]. Numerous laboratory studies have shown that the nitrate can be reduced by MtnZVI [20, 86, 99]. Zhang et al. [86] combined nZVI and pillared Bt (prepared by intercalation with poly(hydroxo 
$\mathrm{Al}(\mathrm{III})$ ) cations) to remove $\mathrm{NO}_{3}{ }^{-}$from the aqueous solution. The adsorption data was fitted well to the Langmuir-Hinshelwood model. This composite could completely remove $\mathrm{NO}_{3}{ }^{-}$at $\mathrm{pH} 7.0$ within $120 \mathrm{~min}$. The nZVI could only remove $62.3 \% \mathrm{NO}_{3}{ }^{-}$under the same condition. Zhao et al. [99] used Mt-nZVI immobilized in sodium alginate (SA/Mt-nZVI) as electron donor-acceptor compounds to enhance the nitrogen $\left(\mathrm{NO}_{3}{ }^{-} \mathrm{N}\right)$ removal from constructed wetland $(\mathrm{CW})$. The removal efficiency of $\mathrm{NO}_{3}^{-}-\mathrm{N} \quad\left(C_{0}=60 \mathrm{mg} \mathrm{L}^{-1}\right)$ by $0.67 \mathrm{mg} \mathrm{L}^{-1} \mathrm{SA} / \mathrm{Mt}-\mathrm{nZVI}$ in $\mathrm{CW}$ was $32.60 \pm 1.9 \%$ at $\mathrm{pH} 7$, which was higher than that by $\mathrm{CW}$ without adding sodium alginate. The introduction of SA/Mt-nZVI could enhance the biological diversity and richness in CW. These results meant that it might be feasible to add SA/Mt-nZVI as a carbon source to treat low $\mathrm{C} / \mathrm{N}$-polluted water.

5.1.4. Halogenated Organic Compounds. Halogenated organic compounds are widely present in industrial wastewater. They have persistence, lipophilicity, high toxicity, and carcinogenicity [100]. They are difficult to be biodegraded and can be enriched in aquatic organisms [101]. Batch experiments have shown that Mt-nZVI could successfully degrade a large number of halogenated organics, such as chlorinated and brominated organics [19, 31]. For example, Pang et al. [73] demonstrated that the removal efficiency of decabromodiphenyl ether $\left(C_{0}=2 \mathrm{mg} \mathrm{L}^{-1}\right)$ by CTMAB-modified Mt-supported nZVI $\left(0.6 \mathrm{gL}^{-1}\right)$ was $98.02 \%$. The adsorption data fitted well to pseudo-first-order reaction. Yu et al. [42] applied TMA-modified smectite-supported nZVI $\left(4 \mathrm{~g} \mathrm{~L}^{-1}\right)$ to reduce $2.5 \mathrm{mg} \mathrm{L}^{-1}$ of DBDE. After a $9 \mathrm{~h}$ reaction, $>80 \%$ DBDE was removed. This composite was shown to be much faster and more efficient for debromination compared to nZVI. Li et al. [40] immobilized CTMA onto Bt to load nZVI. They found that this novel composite had good stability and reusability, which could quickly and completely dechlorinate chlorophenols. The equilibrium adsorption was well described by the Langmuir and Langmuir-Hinshelwood kinetic models.

Recently, nZVI was sulfurated to accelerate reduction efficiency for organochlorine compounds and maintain the stability of composite material in water [102]. For instance, Mt-supported sulfurated nZVI (Mt-S-nZVI) was synthesized [102] and exhibited higher removal efficiency for trichloroethylene $(78.7 \%)$ than sulfurated nZVI and Mt-nZVI. Even aging for 30 days, Mt-S-nZVI could still retain $68.1 \%$ of trichloroethylene.

5.1.5. Dyes. Dyes include high levels of organic contaminants with deep colors. Their degradation products may be carcinogenic and toxic to mammals [69]. Reaction using MtnZVI composite materials to remove dyes has become a promising method [31]. Lin et al. [74] reported that the removal efficiency of acid violet red $\mathrm{B}$ on $\mathrm{Bt}-\mathrm{nZVI}$ was $95.6 \%$ in 9 min under the condition of $2.8 \mathrm{~g} \mathrm{~L}^{-1}$ of Bt-nZVI and $800 \mathrm{mg} \mathrm{L}^{-1}$ acid violet red $\mathrm{B}$ solution. This was higher than that of nZVI (75.1\%). The adsorption was well fitted to the pseudo-first-order model. The degradation of azo dye methyl orange by Bt-nZVI was also fitted well to the pseudo-first-order model [24]. Kerkez et al. [69] demon- strated that Bt-nZVI had a higher adsorption capacity on degrading industrial azo dye Rosso Zetanyl B-NG compared with kaolin- and native clay-supported nZVIs. This was probably because the SSA of Bt was three times that of kaolin and natural clay (Table 2 ).

Mt-nZVI has been combined with microwave treatment for the decolorization of dyes. Microwave treatment can directly heat the reactant molecules and provide more energy to the reaction system, accelerating the efficiency of the degradation reaction [103]. Rao et al. [78] applied Mt-nZVI to remove Rhodamine $6 \mathrm{G}$ ( $\mathrm{Rh} 6 \mathrm{G}$ ) through microwave treatment and revealed that the removal amount of $\mathrm{Rh} 6 \mathrm{G}$ reached $500 \mathrm{mgg}^{-1}$ when the initial $\mathrm{Rh} 6 \mathrm{G}$ concentration was $5000 \mathrm{mg} \mathrm{L}^{-1}$ after degradation for $15 \mathrm{~min}$ by $10 \mathrm{~g} \mathrm{~L}^{-1}$ Mt-nZVI.

5.1.6. Phenolic Compounds. Phenolic derivatives are frequently detected in the wastewater generated by the petrochemical, textile, and pharmaceutical industries [104]. They are highly toxic and harmful to organisms even at low concentrations [105]. Mt-nZVI composites have been proven to be highly efficient for removing phenolic compounds in the laboratory.

Mt-nZVI coupled with oxidants (e.g., $\mathrm{O}_{3}, \mathrm{H}_{2} \mathrm{O}_{2}$, peroxymonosulfate, and persulfate) can enhance the degradation of phenolic compounds [22, 26, 64]. For instance, Bao et al. [89] reported that the adsorption capacity of bisphenol A on BtnZVI was increased in wastewater when $\mathrm{H}_{2} \mathrm{O}_{2}$ was added. Peng et al. [26] investigated tetrabromobisphenol $\mathrm{A}$ and bisphenol A removal using cetyltrimethylammonium bromide- (CTMAB-) modified Mt-supported nZVI in the aqueous solution. When $\mathrm{O}_{3}\left(4 \mathrm{mg} \mathrm{L}^{-1}\right)$ was employed as an oxidant, this composite $\left(0.1 \mathrm{~g} \mathrm{~L}^{-1}\right)$ could remove up to 98.6\% of tetrabromobisphenol $\mathrm{A}$ and $94.7 \%$ of bisphenol $\mathrm{A}$ during $60 \mathrm{~min}$ at $\mathrm{pH} 7$ with an initial contaminant concentration of $10 \mathrm{mg} \mathrm{L}^{-1}$. Yang et al. [64] used Fe-Mt-H $\left(0.4 \mathrm{gL}^{-1}\right)$ as an activator for peroxymonosulfate activation to remove bisphenol A $\left(25 \mathrm{mg} \mathrm{L}^{-1}\right)$ and found that more than $99.3 \%$ bisphenol A was degraded within $3 \mathrm{~h}$ at $\mathrm{pH} 3$.

5.1.7. Other Contaminants. Ren et al. [41] used CTMAmodified Bt to load nZVI. This composite could almost completely reduce nitrobenzene to aniline. The removal followed the Langmuir-Hinshelwood equation. Wu et al. [44] assessed the persulfate activated with OMt-nZVIdegraded sulfamethazine. Sulfamethazine $\left(20 \mathrm{mgL}^{-1}\right)$ was degraded by up to $97 \%$ in $10 \mathrm{~min}$ by using $1.5 \mathrm{mM}$ OMt$\mathrm{nZVI}$ and $4 \mathrm{mM}$ persulfate at $\mathrm{pH}$ 6.8. Additionally, Mt-nZVI also could effectively degrade atrazine [106], amoxicillin [91], and oxytetracycline [75].

The Mt-nZVI is commonly used to treat a single type of contaminant in water. However, Suazo-Hernandez [76] investigated the coremoval of $\mathrm{Se}(\mathrm{VI})$ and $\mathrm{As}(\mathrm{V})$ using MtnZVI. The removal of Se(VI) was fitted well to pseudo-firstorder reaction, while the removal of $\mathrm{As}(\mathrm{V})$ followed pseudo-second-order reaction. The adsorption of $\mathrm{As}(\mathrm{V})$ was the chemisorption process, and the adsorption of $\mathrm{Se}(\mathrm{VI})$ was mainly through the formation of bidentate inner-sphere complexes [107]. The removal efficiency of As(V) (68.43\%) 
was higher compared with that of Se(VI) (42.76\%). This work demonstrated that Mt-nZVI was effective to simultaneously remove both oxyanions (but with a marked preference for $\mathrm{As}(\mathrm{V}))$.

5.2. Remediation of Contaminated Soil. Although nZVI has excellent removal capability for various contaminants from water, the application of nZVI for soil remediation is challenging. Firstly, due to strong magnetic attractive forces, nZVIs often aggregate into micron-sized particles (homoaggregation) or are associated with minerals and organic colloids to form heteroaggregates. These aggregates frequently have low mobility in soils [29]. Secondly, the reactivity of nZVI may be decreased when it is released into the complex soil environment [47]. It is necessary to consider the interference of various soil components and the physicochemical properties of soil during the application of the nZVIs [12]. Finally, nZVI will be oxidized in the soil [108]. As mentioned previously, adding Mt into nZVI can improve the dispersibility of nZVI and reduce the surface corrosion of nZVI. Furthermore, loading nZVI on Mt can also increase the mobility of the nZVI. This is because the attraction between nZVI particles and soil grain surfaces can be eliminated by the strong repulsion between the $\mathrm{Mt}$ and the surfaces $[15,69]$.

The advantages of using Mt-nZVI to remove contaminants from soil have been reported. For example, Soliemanzadeh and Fekri [60] used Bt-nZVI for the treatment of soil with $200 \mathrm{mg} \mathrm{Cr} \mathrm{kg}^{-1}$. The soil samples were incubated at $25^{\circ} \mathrm{C}$ for 5 months and extracted with diethylenetriaminepentaacetic acid solutions. They found that the $\mathrm{Cr}$ was effectively removed by the composite, and the adsorption followed the Langmuir model with a maximum adsorption capacity of $66.10 \mathrm{mgg}^{-1}$. Yu et al. [109] added ethanol to the soil slurry as an organic cosolvent to promote the degradation of decachlorobiphenyl by Bt-nZVI. The results showed that $70 \%$ of decachlorobiphenyl from the soil-water slurry containing $30 \mathrm{mg} \mathrm{L}^{-1}$ of decachlorobiphenyl could be dechlorinated within $13 \mathrm{~h}$ using $5 \mathrm{gL}^{-1}$ of Bt-nZVI when the water/ethanol volume ratio was $1: 1$. Only $18 \%$ of decachlorobiphenyl was removed when ethanol was not added. This is likely because ethanol could increase the degree of decachlorobiphenyl desorption into the liquid phase, thereby enhancing the decachlorobiphenyl dechlorination with nZVI.

Tomasevic et al. [67] used Bt-nZVI and kaolinitesupported $\mathrm{nZVI}$ to immobilize $\mathrm{As}, \mathrm{Pb}$, and $\mathrm{Zn}$ in the contaminated sediment from the Nadela river basin (Serbia). They showed that kaolinite and Bt could prevent the aggregation of nZVI and enhance their mobility in soil media and the treated sediment was safe for disposal. Liu et al. [94] assessed the removal of $\mathrm{Cr}(\mathrm{VI})$ by Bt-nZVI from soil suspended liquid. The maximum removal efficiency of $\mathrm{Cr}$ (VI) $\left(15.68 \mathrm{mg} \mathrm{L}^{-1}\right)$ was $99.75 \%$ at $35^{\circ} \mathrm{C}$ when the dosage of Bt-nZVI was $6 \mathrm{gL}^{-1}$ and $\mathrm{pH}=5$.

\section{Conclusions and Future Challenges}

The use of Mt-nZVI for the removal of contaminants from water and soil has received increasing attention. The com- mon methods to prepare Mt-nZVI include the liquid-phase reduction method, green reduction method, and thermal reduction method. The $n Z V I$ particles have also been loaded on Mt surfaces in a monolayer to form a micro/nanostructure. The introduction of $\mathrm{Mt}$ can improve the dispersion and mobility of nZVI and reduce the particle size and oxidation tendency. The reaction mechanisms of Mt-nZVI with contaminants include adsorption, reduction, oxidation, and precipitation. The reaction is influenced by various environmental factors including $\mathrm{pH}$, temperature, dosage of the adsorbent, and natural organic matter. Mt-nZVI has been shown to have high removal efficiency for contaminants such as heavy metals, uranium, nitrates, halogenated organic compounds, dyes, and phenolic compounds. While Mt-nZVI has been shown as a promising material for water and soil remediation, future work is still necessary to fulfill the large-scale application of Mt-nZVI, as shown in the following:

(i) More attention should be paid to exploring new preparation methods of Mt-nZVI with low cost. For example, it is desired to find some cheap and environmentally friendly reducing agents to replace $\mathrm{NaBH}_{4}$ for producing nZVI. It is also desired to develop methods to improve the adsorption performance of $\mathrm{Mt}$

(ii) The underlying mechanisms between Mt-nZVI and target contaminants at a microscale are still not very clear and required to be further elucidated using modern analytical tools such as X-ray absorption spectroscopy and atomic force microscopy

(iii) The critical factors that affect the removal of contaminants via Mt-nZVI in soil and sediments still need to be identified. The influence mechanisms of these factors are also necessary to be elucidated

(iv) Although Mt can improve the mobility of nZVI in soil, it is still necessary to further improve the mobility of Mt-nZVI with novel methods to improve the in situ remediation efficiency. In addition, the efficiency of soil extraction is an important problem that needs to be addressed during the remediation of contaminated soils using Mt-nZVI

(v) Field experiments are still lacking, which are critical to assess the performance of Mt-nZVI for the in situ remediation of water and soil. Larger-scale field studies are also useful to explore the application of Mt-nZVI at a commercial scale

(vi) It is necessary to extend the reactivity of Mt-nZVI and increase its selectivity to target contaminants. For example, adding a hydrophobic coating to nZVI may extend the reactive lifetime of Mt-nZVI. Functionalization of chemical groups with Mt-nZVI can increase their selectivity to target contaminants

(vii) It is vital to conduct risk assessments of Mt-nZVI to ensure that they are safe while achieving their full 
potential because it is still not clear where they can pose a potential threat to organisms. It is also useful to develop mathematic models to simulate the transport of Mt-nZVI

\section{Data Availability}

All the data used to support the findings of this study is included within the article.

\section{Conflicts of Interest}

The authors declare that they have no conflicts of interest.

\section{Acknowledgments}

We acknowledge the National Natural Science Foundation of China for financial support (grant no. 41922047).

\section{References}

[1] F. L. Fu, D. D. Dionysiou, and H. Liu, "The use of zero-valent iron for groundwater remediation and wastewater treatment: a review," Journal of Hazardous Materials, vol. 267, pp. 194205, 2014.

[2] O. X. Leupin and S. J. Hug, "Oxidation and removal of arsenic (III) from aerated groundwater by filtration through sand and zero-valent iron," Water Research, vol. 39, no. 9, pp. 1729-1740, 2005.

[3] A. Oehmen, R. Viegas, S. Velizarov, M. A. M. Reis, and J. G. Crespo, "Removal of heavy metals from drinking water supplies through the ion exchange membrane bioreactor," Desalination, vol. 199, no. 1-3, pp. 405-407, 2006.

[4] N. Meunier, P. Drogui, C. Montané, R. Hausler, G. Mercier, and J. F. Blais, "Comparison between electrocoagulation and chemical precipitation for metals removal from acidic soil leachate," Journal of Hazardous Materials, vol. 137, no. 1, pp. 581-590, 2006.

[5] X. Zhang, S. Lin, X. Q. Lu, and Z. L. Chen, "Removal of Pb(II) from water using synthesized kaolin supported nanoscale zero-valent iron," Chemical Engineering Journal, vol. 163, no. 3, pp. 243-248, 2010.

[6] B. J. Pan, B. C. Pan, W. M. Zhang, L. Lv, Q. Zhang, and S. Zheng, "Development of polymeric and polymer-based hybrid adsorbents for pollutants removal from waters," Chemical Engineering Journal, vol. 151, no. 1-3, pp. 19-29, 2009.

[7] W. X. Zhang, "Nanoscale iron particles for environmental remediation: an overview," Journal of Nanoparticle Research, vol. 5, no. 3/4, pp. 323-332, 2003.

[8] X. Q. Li, D. W. Elliott, and W. X. Zhang, "Zero-valent iron nanoparticles for abatement of environmental pollutants: materials and engineering aspects," Critical Reviews in Solid State and Materials Sciences, vol. 31, no. 4, pp. 111-122, 2006.

[9] Z. Q. Fang, X. H. Qiu, J. H. Chen, and X. Qiu, "Degradation of the polybrominated diphenyl ethers by nanoscale zero-valent metallic particles prepared from steel pickling waste liquor," Desalination, vol. 267, no. 1, pp. 34-41, 2011.

[10] H. K. Boparai, M. Joseph, and D. M. O’Carroll, "Kinetics and thermodynamics of cadmium ion removal by adsorption onto nano zero valent iron particles," Journal of Hazardous Materials, vol. 1986, pp. 458-465, 2011.

[11] C. Noubactep and S. Care, "On nanoscale metallic iron for groundwater remediation," Journal of Hazardous Materials, vol. 182, no. 1-3, pp. 923-927, 2010.

[12] S. S. Wang, M. Y. Zhao, M. Zhou et al., "Biochar-supported nZVI (nZVI/BC) for contaminant removal from soil and water: a critical review," Journal of Hazardous Materials, vol. 373, pp. 820-834, 2019.

[13] Z. Li, L. Wang, J. Meng et al., "Zeolite-supported nanoscale zero-valent iron: new findings on simultaneous adsorption of $\mathrm{Cd}(\mathrm{II}), \mathrm{Pb}(\mathrm{II})$, and $\mathrm{As}(\mathrm{III})$ in aqueous solution and soil," Journal of Hazardous Materials, vol. 344, pp. 1-11, 2018.

[14] X. Zhao, L. Lv, B. C. Pan, W. Zhang, S. Zhang, and Q. Zhang, "Polymer-supported nanocomposites for environmental application: a review," Chemical Engineering Journal, vol. 170, no. 2-3, pp. 381-394, 2011.

[15] Y. R. Yin, C. Y. Shen, X. Y. Bi, and T. Li, "Removal of hexavalent chromium from aqueous solution by fabricating novel heteroaggregates of montmorillonite microparticles with nanoscale zero-valent iron," Scientific Reports, vol. 10, no. 1, p. 12137, 2020.

[16] L. M. Wu, L. B. Liao, G. C. Lv, and F. Qin, "Stability and pHindependence of nano-zero-valent iron intercalated montmorillonite and its application on Cr(VI) removal," Journal of Contaminant Hhydrology, vol. 179, pp. 1-9, 2015.

[17] B. L. Allen and B. F. Hajek, "Mineral occurrence in soil environments," in Minerals in Soil Environments, pp. 199-278, Soil Science Society of America, Madison, WI, 2nd edition, 1989.

[18] H. Z. Jia and C. Y. Wang, "Comparative studies on montmorillonite-supported zero-valent iron nanoparticles produced by different methods: reactivity and stability," Environmental Technology, vol. 34, no. 1, pp. 25-33, 2013.

[19] H. Z. Jia and C. Y. Wang, "Adsorption and dechlorination of 2,4-dichlorophenol (2,4-DCP) on a multi- functional organosmectite templated zero-valent iron composite," Chemical Engineering Journal, vol. 191, pp. 202-209, 2012.

[20] J. F. Li, Y. M. Li, and Q. L. Meng, "Removal of nitrate by zerovalent iron and pillared bentonite," Journal of Hazardous Materials, vol. 174, no. 1-3, pp. 188-193, 2010.

[21] Y. Y. Zhang, H. Jiang, Y. Zhang, and J. F. Xie, “The dispersitydependent interaction between montmorillonite supported nZVI and $\mathrm{Cr}(\mathrm{VI})$ in aqueous solution," Chemical Engineering Journal, vol. 229, pp. 412-419, 2013.

[22] Z. H. Diao, X. R. Xu, H. Chen et al., "Simultaneous removal of $\mathrm{Cr}(\mathrm{VI})$ and phenol by persulfate activated with bentonitesupported nanoscale zero-valent iron: reactivity and mechanism," Journal of Hazardous Materials, vol. 316, pp. 186193, 2016.

[23] Z. H. Diao, X. R. Xu, D. Jiang et al., "Bentonite-supported nanoscale zero-valent iron/persulfate system for the simultaneous removal of $\mathrm{Cr}(\mathrm{VI})$ and phenol from aqueous solutions," Chemical Engineering Journal, vol. 302, pp. 213-222, 2016.

[24] Z. X. Chen, X. Y. Jin, Z. L. Chen, M. Megharaj, and R. Naidu, "Removal of methyl orange from aqueous solution using bentonite-supported nanoscale zero-valent iron," Journal of Colloid and Interface Science, vol. 363, no. 2, pp. 601-607, 2011.

[25] G. D. Sheng, X. Y. Shao, Y. M. Li et al., "Enhanced removal of uranium(VI) by nanoscale zerovalent iron supported on $\mathrm{Na}$ - 
bentonite and an investigation of mechanism," The Journal of Chemical Physics, vol. 118, no. 16, pp. 2952-2958, 2014.

[26] X. X. Peng, Y. Tian, S. W. Liu, and X. Jia, "Degradation of TBBPA and BPA from aqueous solution using organomontmorillonite supported nanoscale zero-valent iron," Chemical Engineering Journal, vol. 309, pp. 717-724, 2017.

[27] R. A. Crane and T. B. Scott, "Nanoscale zero-valent iron: future prospects for an emerging water treatment technology," Journal of Hazardous Materials, vol. 211-212, pp. 112-125, 2012.

[28] M. Stefaniuk, P. Oleszczuk, and Y. S. Ok, "Review on nano zerovalent iron (nZVI): from synthesis to environmental applications," Chemical Engineering Journal, vol. 287, pp. 618-632, 2016.

[29] D. O'Carroll, B. Sleep, M. Krol, H. Boparai, and C. Kocur, "Nanoscale zero valent iron and bimetallic particles for contaminated site remediation," Advances in Water Resources, vol. 51, pp. 104-122, 2013.

[30] E. Lefevre, N. Bossa, M. R. Wiesner, and C. K. Gunsch, “A review of the environmental implications of_in situ_remediation by nanoscale zero valent iron (nZVI): behavior, transport and impacts on microbial communities," Science of the Total Environment, vol. 565, pp. 889-901, 2016.

[31] N. Ezzatahmadi, G. A. Ayoko, G. J. Millar et al., "Clay-supported nanoscale zero-valent iron composite materials for the remediation of contaminated aqueous solutions: a review," Chemical Engineering Journal, vol. 312, pp. 336350, 2017.

[32] J. L. Xu, Y. L. Li, C. Jing, H. Zhang, and Y. Ning, "Removal of uranium from aqueous solution using montmorillonitesupported nanoscale zero-valent iron," J. Radioanalytical and Nuclear Chemistry, vol. 299, no. 1, pp. 329-336, 2014.

[33] B. W. Hu, F. Ye, X. M. Ren et al., "X-ray absorption fine structure study of enhanced sequestration of U(VI) and Se(IV) by montmorillonite decorated with zero-valent iron nanoparticles," Environmental Science: Nano, vol. 3, no. 6, pp. 14601472, 2016.

[34] J. Wang, G. J. Liu, T. F. Li, and C. Zhou, "Physicochemical studies toward the removal of $\mathrm{Zn}(\mathrm{II})$ and $\mathrm{Pb}(\mathrm{II})$ ions through adsorption on montmorillonite-supported zero-valent iron nanoparticles," RSC Advances, vol. 5, no. 38, pp. 2985929871, 2015.

[35] Z. F. Li, H. P. Dong, Y. L. Zhang, J. Li, and Y. Li, "Enhanced removal of $\mathrm{Ni}$ (II) by nanoscale zero valent iron supported on $\mathrm{Na}$ - saturated bentonite," Journal of Colloid and Interface Science, vol. 497, pp. 43-49, 2017.

[36] Y. M. Li, J. F. Li, and Y. L. Zhang, "Mechanism insights into enhanced $\mathrm{Cr}(\mathrm{VI})$ removal using nanoscale zerovalent iron supported on the pillared bentonite by macroscopic and spectroscopic studies," Journal of Hazardous Materials, vol. 227-228, pp. 211-218, 2012.

[37] Q. Kang, W. Z. Zhou, Q. Li, B. Gao, J. Fan, and D. Shen, "Adsorption of anionic dyes on poly(epicholorohydrin dimethylamine) modified bentonite in single and mixed dye solutions," Applied Clay Science, vol. 45, no. 4, pp. 280-287, 2009.

[38] S. L. Tian, L. Z. Zhu, and Y. Shi, "Characterization of sorption mechanisms of VOCs with organobentonites using a LSER approach," Environmental Science \& Technology, vol. 38, no. 2, pp. 489-495, 2004.

[39] H. Liu, X. Ruan, D. Y. Zhao, X. Fan, and T. Feng, "Enhanced adsorption of 2,4-dichlorophenol by nanoscale zero-valent iron loaded on bentonite and modified with a cationic surfactant," Industrial \& Engineering Chemistry Research, vol. 56, no. 1, pp. 191-197, 2017.

[40] Y. M. Li, Y. Zhang, J. F. Li, and X. Zheng, "Enhanced removal of pentachlorophenol by a novel composite: nanoscale zero valent iron immobilized on organobentonite," Environmental Pollution, vol. 159, no. 12, pp. 3744-3749, 2011.

[41] C. X. Ren, Y. M. Li, J. F. Li, G. Sheng, L. Hu, and X. Zheng, "Immobilization of nanoscale zero valent iron on organobentonite for accelerated reduction of nitrobenzene," Journal of Chemical Technology \& Biotechnology, vol. 89, no. 12, pp. 1961-1966, 2014.

[42] K. Yu, C. Gu, S. A. Boyd et al., "Rapid and extensive debromination of decabromodiphenyl ether by smectite claytemplated subnanoscale zero-valent iron," Environmental Science \& Technology, vol. 46, no. 16, pp. 8969-8975, 2012.

[43] P. X. Wu, S. Z. Li, L. T. Ju et al., "Mechanism of the reduction of hexavalent chromium by organo-montmorillonite supported iron nanoparticles," Journal of Hazardous Materials, vol. 219-220, pp. 283-288, 2012.

[44] J. X. Wu, B. Wang, L. Blaney et al., "Degradation of sulfamethazine by persulfate activated with organo- montmorillonite supported nano-zero valent iron," Chemical Engineering Journal, vol. 361, pp. 99-108, 2019.

[45] C. B. Wang and W. X. Zhang, "Synthesizing nanoscale iron particles for rapid and complete dechlorination of TCE and PCBs," Environmental Science \& Technology, vol. 31, no. 7, pp. 2154-2156, 1997.

[46] Y. Z. Zhou, T. Wang, D. Zhi et al., "Applications of nanoscale zero-valent iron and its composites to the removal of antibiotics: a review," Journal of Materials Science, vol. 54, no. 19, pp. 12171-12188, 2019.

[47] X. Zhao, W. Liu, Z. Q. Cai, B. Han, T. Qian, and D. Zhao, “An overview of preparation and applications of stabilized zerovalent iron nanoparticles for soil and groundwater remediation," Water Research, vol. 100, pp. 245-266, 2016.

[48] R. L. Zhu, Q. Z. Chen, Q. Zhou, Y. Xi, J. Zhu, and H. He, "Adsorbents based on montmorillonite for contaminant removal from water: a review," Applied Clay Science, vol. 123, pp. 239-258, 2016.

[49] T. Shahwan, Ç. Üzüm, A. E. Eroğlu, and I. Lieberwirth, "Synthesis and characterization of bentonite/iron nanoparticles and their application as adsorbent of cobalt ions," Applied Clay Science, vol. 47, no. 3-4, pp. 257-262, 2010.

[50] C. Yu, J. C. Shao, X. Q. Cai, and X. N. Yu, "Research on preparation of nanoscale iron supported by bentonite and its remediation of lead ions," Digest Journal of Nanomaterials and Biostructures, vol. 13, no. 1, pp. 31-38, 2018.

[51] L. N. Shi, X. Zhang, Z. L. Chen et al., "Removal of chromium (VI) from wastewater using bentonite-supported nanoscale zero-valent iron," Water Research, vol. 45, no. 2, pp. 886892, 2011.

[52] W. L. Yan, H. L. Lien, B. E. Koel, and W. X. Zhang, "Iron nanoparticles for environmental clean-up: recent developments and future outlook," Environmental Science-Processes \& Impacts, vol. 15, no. 1, pp. 63-77, 2013.

[53] J. Wang, G. J. Liu, C. C. Qi, and C. Zhou, "Synthesis and characterization of montmorillonite-supported zero-valent iron nanoparticles with application for preconcentration of zinc," Analytical Letters, vol. 49, no. 17, pp. 27662782, 2016. 
[54] Z. Q. Fang, X. H. Qiu, J. H. Chen, and X. Qiu, "Degradation of metronidazole by nanoscale zero-valent metal prepared from steel pickling waste liquor," Applied Catalysis B: Environmental, vol. 100, no. 1-2, pp. 221-228, 2010.

[55] Y. Xiong, Soil colloid (volume II): soil colloid research method, Science press, 1984.

[56] C. Shen, L. Wu, S. W. Zhang, H. Ye, B. Li, and Y. Huang, "Heteroaggregation of microparticles with nanoparticles changes the chemical reversibility of the microparticles' attachment to planar surfaces," Journal of Colloid and Interface Science, vol. 421, pp. 103-113, 2014.

[57] C. Shen, Y. Jin, J. Zhuang, T. Li, and B. Xing, "Role and importance of surface heterogeneities in transport of particles in saturated porous media," Critical Reviews in Environmental Science and Technology, vol. 50, no. 3, pp. 244-329, 2020.

[58] A. Singh, D. Jain, M. K. Upadhyay, N. Khandelwal, and H. N. Verma, "Green synthesis of silver nanoparticles using Argemone mexicana leafextract and evaluation of their antimicrobial activities," Digest Journal of Nanomaterials and Biostructures, vol. 5, pp. 483-489, 2010.

[59] M. Chrysochoou, C. P. Johnston, and G. A. Dahal, "Comparative evaluation of hexavalent chromium treatment in contaminated soil by calcium polysulfide and green-tea nanoscale zero-valent iron," Journal of Hazardous Materials, vol. 201, pp. 33-42, 2012.

[60] A. Soliemanzadeh and M. Fekri, "The application of green tea extract to prepare bentonite-supported nanoscale zero-valent iron and its performance on removal of $\mathrm{Cr}(\mathrm{VI})$ : effect of relative parameters and soil experiments," Microporous and Mesoporous Materials, vol. 239, pp. 60-69, 2017.

[61] S. Senapati, A. Ahmad, M. I. Khan, M. Sastry, and R. Kumar, "Extracellular biosynthesis of bimetallic $\mathrm{Au}-\mathrm{Ag}$ alloy nanoparticles," Small, vol. 1, no. 5, pp. 517-520, 2005.

[62] S. H. Ho, S. H. Zhua, and J. S. Chang, "Recent advances in nanoscale-metal assisted biochar derived from waste biomass used for heavy metals removal," Bio/Technology, vol. 246, pp. 123-134, 2017.

[63] L. B. Hoch, E. J. B. W. Mack, B. W. Hydutsky, J. M. Hershman, J. M. Skluzacek, and T. E. Mallouk, "Carbothermal synthesis of carbon-supported nanoscale zero-valent iron particles for the remediation of hexavalent chromium," Environmental Science \& Technology, vol. 42, no. 7, pp. 2600-2605, 2008.

[64] S. H. Yang, P. X. Wu, J. Q. Liu, M. Chen, Z. Ahmed, and $\mathrm{N}$. Zhu, "Efficient removal of bisphenol A by superoxide radical and singlet oxygen generated from peroxymonosulfate activated with $\mathrm{Fe}^{0}$-montmorillonite," Chemical Engineering Journal, vol. 350, pp. 484-495, 2018.

[65] Q. Q. Chen, P. Wu, Y. Y. Li, N. Zhu, and Z. Dang, "Heterogeneous photo-Fenton photodegradation of reactive brilliant orange X-GN over iron-pillared montmorillonite under visible irradiation," Journal of Hazardous Materials, vol. 168, no. 2-3, pp. 901-908, 2009.

[66] Y. M. Li, Y. Zhang, J. F. Li, G. Sheng, and X. Zheng, "Enhanced reduction of chlorophenols by nanoscale zerovalent iron supported on organobentonite," Chemosphere, vol. 92, no. 4, pp. 368-374, 2013.

[67] D. D. Tomašević, G. Kozma, D. V. Kerkez et al., “Toxic metal immobilization in contaminated sediment using bentoniteand kaolinite-supported nano zero-valent iron," Journal of Nanoparticle Research, vol. 16, no. 8, p. 2548, 2014.
[68] L. N. Shi, Y. Zhou, Z. L. Chen, M. Megharaj, and R. Naidu, "Simultaneous adsorption and degradation of $\mathrm{Zn}^{2+}$ and $\mathrm{Cu}^{2+}$ from wastewaters using nanoscale zero-valent iron impregnated with clays," Environmental Science and Pollution Rresearch, vol. 20, no. 6, pp. 3639-3648, 2013.

[69] D. V. Kerkez, D. D. Tomašević, G. Kozma et al., “Three different clay-supported nanoscale zero-valent iron materials for industrial azo dye degradation: a comparative study," Journal of the Taiwan Institute of Chemical Engineers, vol. 45, no. 5, pp. 2451-2461, 2014.

[70] X. G. Li, Y. Zhao, B. Xi et al., "Removal of nitrobenzene by immobilized nanoscale zero-valent iron: effect of clay support and efficiency optimization," Applied Surface Science, vol. 370, pp. 260-269, 2016.

[71] B. Kornilovych, I. Kovalchuk, V. Tobilko, and S. Ubaldini, "Uranium removal from groundwater and wastewater using clay-supported nanoscale zero-valent iron," Metals, vol. 10, no. 11, p. 1421, 2020.

[72] M. D. Fan, P. Yuan, T. H. Chen et al., "Synthesis, characterization and size control of zerovalent iron nanoparticles anchored on montmorillonite," Chinese Science Bulletin, vol. 55, no. 11, pp. 1092-1099, 2010.

[73] Z. H. Pang, M. Y. Yan, X. S. Jia, Z. Wang, and J. Chen, "Debromination of decabromodiphenyl ether by organomontmorillonite-supported nanoscale zero-valent iron: preparation, characterization and influence factors," Journal of Environmental Sciences, vol. 26, no. 2, pp. 483-491, 2014.

[74] Y. M. Lin, Z. X. Chen, Z. L. Chen, M. Megharaj, and R. Naidu, "Decoloration of acid violet red B by bentonite-supported nanoscale zero-valent iron: reactivity, characterization, kinetics and reaction pathway," Applied Clay Science, vol. 93-94, pp. 56-61, 2014.

[75] M. L. Tran, S. W. Deng, C. C. Fu, and R. S. Juang, "Efficient removal of antibiotic oxytetracycline from water using optimized montmorillonite-supported zero-valent iron nanocomposites," Environmental Science and Pollution Research, vol. 27, no. 24, pp. 30853-30867, 2020.

[76] J. Suazo-Hernández, K. Manquián-Cerda, M. de la Luz Mora et al., "Efficient and selective removal of $\mathrm{Se}^{\mathrm{VI}}$ and $\mathrm{As}^{\mathrm{V}}$ mixed contaminants from aqueous media by montmorillonitenanoscale zero valent iron nanocomposite," Journal of Hazardous Materials, vol. 403, p. 123639, 2021.

[77] N. Arancibia-Miranda, S. E. Baltazar, A. García et al., "Nanoscale zero valent supported by zeolite and montmorillonite: template effect of the removal of lead ion from an aqueous solution," Journal of Hazardous Materials, vol. 301, pp. 371-380, 2016.

[78] W. X. Rao, H. Liu, G. H. Lv, D. Wang, and L. Liao, "Effective degradation of $\mathrm{Rh} 6 \mathrm{G}$ using montmorillonite-supported nano zero-valent iron under microwave treatment," Materials, vol. 11, no. 11, p. 2212, 2018.

[79] Y. M. Li, W. Cheng, G. D. Sheng et al., "Synergetic effect of a pillared bentonite support on $\mathrm{Se}(\mathrm{VI})$ removal by nanoscale zero valent iron," Applied Catalysis B: Environmental, vol. 174-175, pp. 329-335, 2015.

[80] M. Y. Zhang, K. X. Yi, X. W. Zhang, P. Han, W. Liu, and M. Tong, "Modification of zero valent iron nanoparticles by sodium alginate and bentonite: enhanced transport, effective hexavalent chromium removal and reduced bacterial toxicity," Journal of Hazardous Materials, vol. 388, p. 121822, 2020.

[81] L. N. Shi, Y. M. Lin, X. Zhang, and Z. L. Chen, "Synthesis, characterization and kinetics of bentonite supported nZVI 
for the removal of $\mathrm{Cr}(\mathrm{VI})$ from aqueous solution," Chemical Engineering Journal, vol. 171, no. 2, pp. 612-617, 2011.

[82] S. Bhowmick, S. Chakraborty, P. Mondal et al., "Montmorillonite-supported nanoscale zero-valent iron for removal of arsenic from aqueous solution: kinetics and mechanism," Chemical Engineering Journal, vol. 243, pp. 14-23, 2014.

[83] P. Yuan, M. D. Fan, D. Yang et al., "Montmorillonite-supported magnetite nanoparticles for the removal of hexavalent chromium [Cr(VI)] from aqueous solutions," Journal of Hazardous Materials, vol. 166, no. 2-3, pp. 821-829, 2009.

[84] X. Liu, Z. Cao, Z. Yuan et al., "Insight into the kinetics and mechanism of removal of aqueous chlorinated nitroaromatic antibiotic chloramphenicol by nanoscale zero-valent iron," Chemical Engineering Journal, vol. 334, pp. 508-518, 2018.

[85] N. A. Zarime, W. Z. W. Yaacob, and H. Jamil, Removal of heavy metals using bentonite supported nano-zero valent iron particles, AIP Conference Proceedings, 2018.

[86] Y. Zhang, Y. M. Li, J. F. Li, L. Hu, and X. Zheng, "Enhanced removal of nitrate by a novel composite: nanoscale zero valent iron supported on pillared clay," Chemical Engineering Journal, vol. 171, no. 2, pp. 526-531, 2011.

[87] H. Dong, J. Deng, Y. Xie et al., "Stabilization of nanoscale zero-valent iron (nZVI) with modified biochar for $\mathrm{Cr}(\mathrm{VI})$ removal from aqueous solution," Journal of Hazardous Materials, vol. 332, pp. 79-86, 2017.

[88] J. C. Shao, X. N. Yu, M. Zhou, X. Cai, and C. Yu, "Nanoscale zero-valent iron decorated on bentonite/graphene oxide for removal of copper ions from aqueous solution," Materials, vol. 11, no. 6, p. 945, 2018.

[89] T. Bao, M. M. Damtie, A. Hosseinzadeh et al., "Bentonitesupported nano zero-valent iron composite as a green catalyst for bisphenol A degradation: preparation, performance, and mechanism of action," Journal of Environmental Management, vol. 260, p. 110105, 2020.

[90] Y. D. Zou, X. X. Wang, A. Khan et al., "Environmental remediation and application of nanoscale zero-valent iron and its composites for the removal of heavy metal ions: a review," Environmental Science \& Technology, vol. 50, no. 14, pp. 7290-7304, 2016.

[91] X. L. Weng, W. L. Cai, S. Lin, and Z. Chen, "Degradation mechanism of amoxicillin using clay supported nanoscale zero- valent iron," Applied Clay Science, vol. 147, pp. 137$142,2017$.

[92] J. Wang, "Adsorption of aqueous neodymium, europium, gadolinium, terbium, and yttrium ions onto nZVI-montmorillonite: kinetics, thermodynamic mechanism, and the influence of coexisting ions," Environmental Science and Pollution Research, vol. 25, no. 33, pp. 33521-33537, 2018.

[93] L. L. Chen, S. J. Feng, D. L. Zhao, S. Chen, F. Li, and C. Chen, "Efficient sorption and reduction of $\mathrm{U}(\mathrm{VI})$ on zero-valent iron-polyaniline- graphene aerogel ternary composite," Journal of Colloid and Interface Science, vol. 490, pp. 197-206, 2017.

[94] S. C. Liu, H. J. Gao, R. Cheng et al., "Study on influencing factors and mechanism of removal of $\mathrm{Cr}(\mathrm{VI})$ from soil suspended liquid by bentonite-supported nanoscale zero-valent iron," Scientific Reports, vol. 10, no. 1, p. 8831, 2020.

[95] Z. Wang, G. Chen, X. R. Wang, S. Li, Y. Liu, and G. Yang, "Removal of hexavalent chromium by bentonite supported organosolv lignin- stabilized zero-valent iron nanoparticles from wastewater," Journal Cleaner Production, vol. 267, p. 122009, 2020.

[96] Z. X. Chi, Z. Wang, H. Q. Chu, P. Bin, and L. Lucian, "Bentonite-supported nanoscale zero-valent iron granulated electrodes for industrial wastewater remediation," RSC Advances, vol. 7, no. 70, pp. 44605-44613, 2017.

[97] F. Y. Wang, W. W. Yang, F. Y. Zheng, and Y. Sun, "Removal of $\mathrm{Cr}$ (VI) from simulated and leachate wastewaters by bentonite-supported zero-valent iron nanoparticles," International Journal of Environmental Research and Public Health, vol. 15, no. 10, p. 2162, 2018.

[98] S. N. Milmile, J. V. Pande, S. Karmakar, A. Bansiwal, T. Chakrabarti, and R. B. Biniwale, "Equilibrium isotherm and kinetic modeling of the adsorption of nitrates by anion exchange Indion NSSR resin," Desalination, vol. 276, no. 13, pp. 38-44, 2011.

[99] Y. F. Zhao, X. Cao, X. S. Song et al., "Montmorillonite supported nanoscale zero-valent iron immobilized in sodium alginate (SA/Mt-NZVI) enhanced the nitrogen removal in vertical flow constructed wetlands (VFCWs)," Bio/Technology, vol. 267, pp. 608-617, 2018.

[100] M. J. Ahmed and S. K. Theydan, “Adsorption of_p_-chlorophenol onto microporous activated carbon from _Albizia lebbeck_ seed pods by one-step microwave assisted activation," Journal of Analytical and Applied Pyrolysis, vol. 100, pp. 253-260, 2013.

[101] M. Tobajas, V. M. Monsalvo, A. F. Mohedano, and J. J. Rodriguez, "Enhancement of cometabolic biodegradation of 4chlorophenol induced with phenol and glucose as carbon sources by _Comamonas testosteroni_," Journal of Environmental Management, vol. 95, pp. S116-S121, 2012.

[102] B. D. Xu, D. C. Li, T. T. Qian, and H. Jiang, "Boosting the activity and environmental stability of nanoscale zero-valent iron by montmorillonite supporting and sulfidation treatment," Chemical Engineering Journal, vol. 387, p. 124063, 2020.

[103] L. Olmedo, P. Hourquebie, and F. Jousse, "Microwave absorbing materials based on conducting polymers," Advanced Materials, vol. 5, no. 5, pp. 373-377, 1993.

[104] Y. Park, G. Ayoko, E. Horváth, R. Kurdi, J. Kristof, and R. L. Frost, "Structural characterisation and environmental application of organoclays for the removal of phenolic compounds," Journal of Colloid and Interface Science, vol. 393, pp. 319-334, 2013.

[105] J. Olejniczak, J. Staniewski, and J. Szymanowski, "Extraction of phenols and phenyl acetates with diethyl carbonate," Analytica Chimica Acta, vol. 535, no. 1-2, pp. 251-257, 2005.

[106] Y. Zhang, Y. M. Li, and X. M. Zheng, "Removal of atrazine by nanoscale zero valent iron supported on organobentonite," Science of the Total Environment, vol. 409, no. 3, pp. 625630, 2011.

[107] F. Sun, K. A. Osseo-Asare, Y. Chen, and B. A. Dempsey, "Reduction of As(V) to As(III) by commercial ZVI or As(0) with acid-treated ZVI," Journal of Hazardous Materials, vol. 196, pp. 311-317, 2011.

[108] S. M. Ponder, J. G. Darab, and T. E. Mallouk, "Remediation of $\mathrm{Cr}(\mathrm{VI})$ and $\mathrm{Pb}(\mathrm{II})$ aqueous solutions using supported, nanoscale zero-valent iron," Environmental Science \& Technology, vol. 34, no. 12, pp. 2564-2569, 2000. 
[109] K. Yu, G. D. Sheng, and W. McCall, "Cosolvent effects on dechlorination of soil-sorbed polychlorinated biphenyls using bentonite clay-templated nanoscale zero valent iron," Environmental Science \& Technology, vol. 50, no. 23, pp. 12949-12956, 2016.

[110] M. Reinholdt, J. Miehé-Brendlé, L. Delmotte et al., "Fluorine route synthesis of montmorillonites containing $\mathrm{Mg}$ or $\mathrm{Zn}$ and characterization by XRD, thermal analysis, MAS NMR, and EXAFS spectroscopy," European Journal of Inorganic Chemistry, vol. 2001, no. 11, pp. 2831-2841, 2001. 